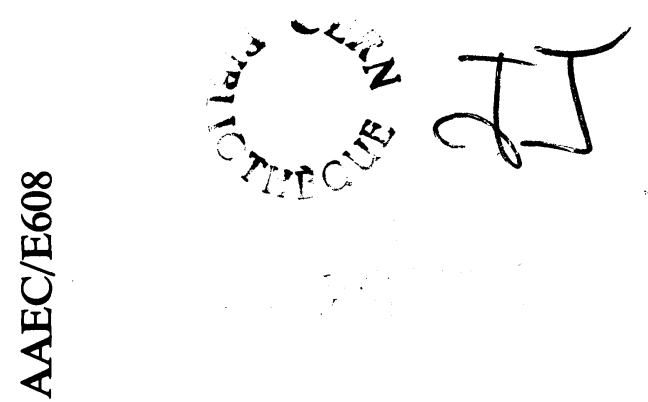

AAEC-E 608

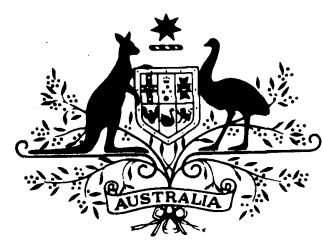

$c_{1}$

AAEC/E608

\title{
AUSTRALIAN ATOMIC ENERGY COMMISSION RESEARCH ESTABLISHMENT
}

LUCAS HEIGHTS RESEARCH LABORATORIES

DOUBLE DIFFERENTIAL CROSS SECTIONS FOR ELECTRON EJECTION FROM HELIUM BY FAST PROTONS

by

CERN LIBRARIES, GENEVA

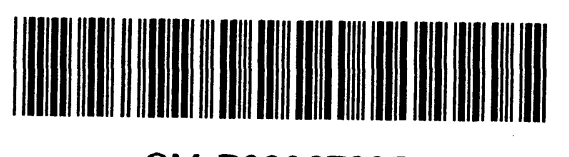

CM-P00067985

D.K. GIBSON

*ID. REID

* AINSE fellow 1982-84; now with TRIUMF (Tri-University Meson Facility), Vancouver, Canada.

DECEMBER 1985

ISBN 0642598215 
AUSTRALIAN ATOMIC ENERGY COMMISSION

RESEARCH ESTABLISHMENT

LUCAS HEIGHTS RESEARCH LABORATORIES

\title{
DOUBLE DIFFERENTIAL CROSS SECTIONS FOR ELECTRON EJECTION FROM HELIUM BY FAST PROTONS
}

by

D.K. GIBSON

*I.D. REID

\begin{abstract}
Measurements of the angular and energy distributions of electrons ejected from helium atoms by protons with energies between 20 and $100 \mathrm{keV}$ are presented in tabular and graphical form. The electron energy range is between 5 and $100 \mathrm{eV}$ and the angular range is between 0 and $100^{\circ}$. The distributions have been converted to double differential cross sections by normalisation against other published data. An analysis of the accuracy of the results is presented.
\end{abstract}

* AINSE fellow 1982-84; now with TRIUMF (Tri-University Meson Facility), Vancouver, Canada. 
National Library of Australia card number and ISBN 0642598215

The following descriptors have been selected from the INIS Thesaurus to describe the subject content of this report for information retrieval purposes. For further details please refer to IAEA-INIS-12 (INIS: Manual for Indexing) and IAEA-INIS-13 (INIS: Thesaurus) published in Vienna by the International Atomic Energy Agency.

ANGULAR DISTRIBUTION; DIFFERENTIAL CROSS SECTIONS; ELECTRONS; EXPERIMENTAL DATA; HELIUM; IONIZATION; KEV RANGE 10-100; PROTONS 


\section{CONTENTS}

\section{INTRODUCTION}

2. DATA REDUCTION AND ESTIMATION OF ERRORS

3. RESULTS

4. CONCLUSIONS

5. ACKNOWLEDGEMENTS 3

6. REFERENCES

Table $1 \quad$ Example of basic measurement set

Table 2 Example of relative normalisation factors

Table 3 Example of optimised relative normalisation factors $v$. electron energy 6

$\begin{array}{lll}\text { Table } 4 & \text { Total ionisation cross section } & 6\end{array}$

Table 5 Cross sections for $20 \mathrm{keV} \mathrm{H}^{+}$on $\mathrm{He} \quad 7$

Table 6 Cross sections for $30 \mathrm{keV} \mathrm{H}^{+}$on $\mathrm{He} \quad 8$

Table 7 Cross sections for $40 \mathrm{keV} \mathrm{H}^{+}$on $\mathrm{He} \quad 9$

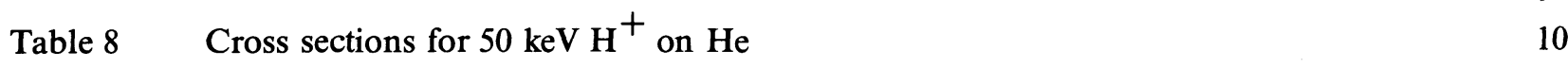

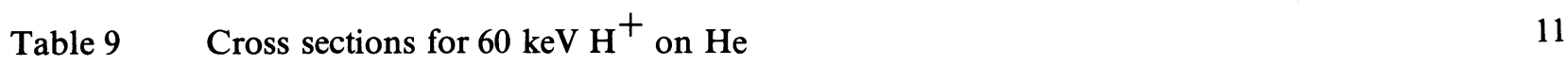

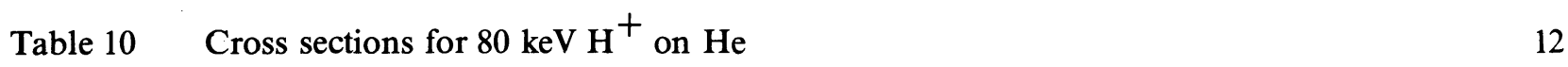

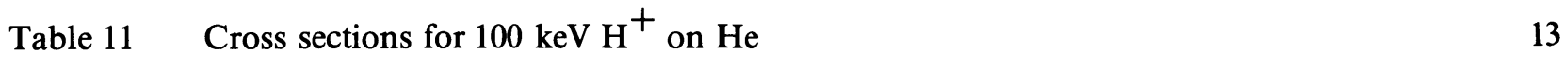

$\begin{array}{lll}\text { Figure } 1 & \text { Reduced count as a function of target gas pressure } & 15\end{array}$

Figure 2 Un-normalised and normalised angular distribution measurements 16

$\begin{array}{lll}\text { Figure } 3 & \text { Variation of cross section with electron energy } & 17\end{array}$

$\begin{array}{lll}\text { Figure } 4 & \text { Total ionisation cross sections } & 18\end{array}$

$\begin{array}{lll}\text { Figure } 5 & 20 \mathrm{keV} \mathrm{H}^{+} \text {double differential cross section } & 19\end{array}$

Figure $6 \quad 30 \mathrm{keV} \mathrm{H}^{+}$double differential cross section $\quad 20$

Figure $7 \quad 40 \mathrm{keV} \mathrm{H}^{+}$double differential cross section $\quad 21$

Figure $8 \quad 50 \mathrm{keV} \mathrm{H}^{+}$double differential cross section $\quad 22$

Figure $9 \quad 60 \mathrm{keV} \mathrm{H}^{+}$double differential cross section $\quad 23$

Figure $10 \quad 80 \mathrm{keV} \mathrm{H}^{+}$double differential cross section $\quad 24$

Figure $11 \quad 100 \mathrm{keV} \mathrm{H}^{+}$double differential cross section $\quad 25$ 


\section{INTRODUCTION}

Results of a series of measurements of the double differential cross sections, $\partial \sigma(\varepsilon, \theta) \partial \varepsilon \partial \Omega$, for ionisation of helium atoms by protons, where $\varepsilon$ is the energy of the freed electron and $\theta$ is its ejection angle, are given in tabular and graphical form. The electron energy range is from 5 to $100 \mathrm{eV}$ and the scattering angles, measured with respect to the proton velocity, are in the range 0 to $100^{\circ}$. Seven proton energies were used between 20 and $100 \mathrm{keV}$.

This set of measurements extends existing data into the region between 0 and $10^{\circ}$. The peak in the cross section at zero degrees and at the energy at which the electron has the same velocity as the incident proton (due to the process of charge exchange into the continuum) is therefore examined in detail. A comparison of our data with other experimental and theoretical data will be published elsewhere [Gibson and Reid 1986].

These measurements were made in helium to establish a basis for similar measurements using target molecules such as $\mathrm{O}_{2}, \mathrm{~N}_{2}, \mathrm{CO}_{2}$ and $\mathrm{H}_{2} \mathrm{O}$ where the information is required for radiation dosimetry calculations [Kim 1975]. In the proton energy range 20 to $100 \mathrm{keV}$, extensive cross sections have so far been available only for helium.

A comprehensive description is given of the data reduction techniques together with an evaluation of the accuracy of the measurements.

\section{DATA REDUCTION AND ESTIMATION OF ERRORS}

The measurements were made with a $30^{\circ}$ plane electrostatic analyser, used in such a way that measurements could be made simultaneously with a number of detectors at different angles. As descriptions of this apparatus have been published [Gibson and Reid 1984, Gibson and Petersen 1978], reference is made only to the measurement procedure necessary for an analysis of the accuracy of the results.

Nine electron detectors were used to make the measurements. This set of detectors was moved to 16 angular positions spaced about $1^{\circ}$ apart. Therefore, for each electron and proton energy, nine curves of intensity versus angle were obtained. Each curve covered a region of about $16^{\circ}$ and slightly overlapped the neighbouring curves. This measurement was repeated for a number of electron energies (generally about 15) and seven proton energies.

Each intensity measurement was derived, in fact, from two sets of four measurements of electron counts (per unit proton current) for four values of target gas pressure. For one set, the gas was introduced through a jet (signal mode) and for the other as a general background. This brief description of the raw data allows us to follow the various steps of data processing and examine the accumulation of errors.

A sample measurement taken with one detector is shown in table 1 and figure 1. Although quoted in $\mathrm{mPa}$, the gas pressure is only nominal as it was measured with an ion gauge that was not necessarily calibrated for helium. The slopes of the electron count rate (per unit beam current) versus pressure were calculated using a least-squares fitting procedure. In this procedure, the variance in each count was taken to be the sum of the count (counting statistics) and an effective count uncertainty due to an estimated uncertainty of $10^{-2} \mathrm{mPa}$ in the pressure. The variances in the calculated slopes are shown. The unnormalised cross section is the difference between the signal and background slopes; the variance in this value is the sum of the variances in the two slopes. The results of these calculations are shown in figure 2. In practice, the slopes calculated from some sets of data were perturbed by serious errors in one or more of the counts, due perhaps to the pick-up of external noise by the detector system. Such occurrences were detected by a statistical test and all data from them rejected.

The next step in the data reduction was to normalise the nine sections of the cross section curve versus scattering angle against one another. The curves for the different detectors are displaced from each other because of differences in counting efficiencies in the detectors (figure 2). These differences could be a combination of intrinsic differences in channel multiplier efficiencies and geometrical differences, leading to variations in collection efficiency.

The obvious way to find the relative normalisation factors would be to find the ratios between pairs of overlapping points on adjacent curves. There is a minor argument against this technique; the angle coordinates do not correspond exactly, owing to the trigonometrical transformations relating scattering angle and detector position. More important is the undue reliance that would be put on the accuracy of the two 
overlapping points. It is also possible that one of the points might have been rejected, as mentioned above, due to non-linear variation with pressure. Consequently, a method was adopted in which all the points from two adjacent detectors were least-squares fitted to a common curve, with the points from one detector having an adjustable multiplier included as part of the fitting procedure. This multiplier is the relative normalisation factor, its value and variance are obtained from the least-squares fitting procedure. In practice, in view of the large variation of cross section with scattering angle, the fitting was performed on the logarithms of the cross sections, and the floating factor was additive. The common curve for fitting adjacent curves was cubic for the measurements near zero degrees and quadratic elsewhere. In general, the form of the curve produced insignificant differences in the normalisation factors.

The results of such a fitting procedure are shown in figure 2 , together with the original unnormalised data. Table 2 shows the relative normalisation factors and their standard deviations for each detector for one particular electron energy as a typical example. As the errors in these normalisation factors are cumulative, the final relative error estimate from one end of the composite curve to the other is given by the square root of the sum of the squares of the individual error estimates. Therefore, as may be readily calculated from the figures for the example in table 2, the maximum probable error in the ratio of the cross sections at $0^{\circ}$ (detector 1 ) and $100^{\circ}$ (detector 9) is seven per cent.

The normalisation factors relating the responses of the nine detectors to one another are now defined for each electron energy, thus allowing the angular distribution of the cross section at each electron energy to be defined. However, the energy dependence of the cross section is based on the arbitrary assumption that the response of detector 1 is independent of energy. In a further calculation, this assumption may be replaced by one in which the average response of all the detectors is energy independent.

The calculations so far yield a matrix of normalisation coefficients $F_{i j}$ which apply to the $i$ th energy and the $j$ th detector. These coefficients may be multiplied by energy-dependent factors $a_{i}$ which will not alter the established angular dependence of the cross section but which will alter the energy dependence (till now based on detector 1 having no energy bias). A new set of normalisation factors,

$$
G_{i j}=a_{i} F_{i j} \text {, }
$$

may be established, where the values of $a_{i}$ are chosen so that

$$
\Sigma_{i} \Sigma_{j}\left(G_{i j}-G_{j}\right)^{2} / G_{j}
$$

is minimised, where $G_{j}$ is the mean value of the coefficient for the $j$ th detector, given by

$$
G_{j}=\left(\Sigma_{i} G_{i j}\right) / n_{j} \text {. }
$$

In this way, the average response of all the detectors is forced to be energy independent.

This procedure revealed that detectors 1 and 2 were anomalous, their variations with energy being much greater than those for the other seven detectors. Detector 1 was a small electron multiplier, containing some ferromagnetic material which could be responsible for its energy-dependent response. Although detector 2 was a channeltron, similar to detectors 3 to 9 , it had shown some instability, probably due to surface charging effects. Therefore detectors 1 and 2 were excluded from the minimisation procedure. The resulting normalisation coefficients can be separated into two parts: an average for each detector and an array of energy-dependent correction factors, $C_{i j}$. This is done solely to demonstrate the behaviour of the factors as, ideally, the $C_{i j}$ should all be unity, and their departure from unity is a measure of the experimental uncertainty. A typical sample of a $C_{i j}$ array is shown in table 3 . The means taken over the nine detectors have been calculated as well as the standard deviations from unity, that is

$$
\Sigma_{j}\left(C_{i j}\right) / n_{j} \text { and } \sqrt{\Sigma_{j}\left(C_{i j}-1.0\right)^{2} / n_{j}} \text {. }
$$

These values show that for energies above $10 \mathrm{eV}$, errors of 13 per cent can be expected, whereas for 10 and 5 $\mathrm{eV}$ the errors rise to 40 and 80 per cent respectively.

The above techniques were applied to the data to obtain best estimates of the cross sections. The fact that these cross sections and those of Rudd et al. [1976] agree in their energy dependence (see, for example, figure 3) corroborates the assumption that the average response of the detectors is independent of energy. A further idea of the accuracy of the measured energy dependence can be gained from a comparison of several independent measurements for one $\mathrm{H}^{+}$energy (figure 3). The low energy measurements in some of these series are poor because they were made during the period of apparatus development, when one of the greatest problems was the effect of stray surface potentials. However, as can be seen from figure 3 , the 
above estimates of the error in the shape of the energy curve are reasonable.

Finally, the cross sections were normalised to absolute values by comparing the total ionisation cross section, obtained by evaluating

$$
2 \pi \int_{0}^{\pi} \int_{0}^{\infty} \sigma(\varepsilon, \theta) \sin \theta d \varepsilon d \theta,
$$

with the data of de Heer et al. [1966]. Obviously, the cross sections had to be extrapolated from 100 to $180^{\circ}$ and from 5 to $0 \mathrm{eV}$. The latter was the greatest source of error. The normalisation factor required to yield optimum agreement with the total ionisation cross section curve was applied to the double differential cross sections to bring them onto an absolute scale. The total cross sections are compared with other data in figure 4. The values of the total cross sections are presented in table 4; these data may be used for renormalising the differential cross sections if any future information shows this to be necessary.

\section{RESULTS}

The data reduction techniques described above have been used to derive best estimates of the double differential cross sections from the raw data. The cross sections are normalised through the integrated total ionisation cross section to published experimental data and are expressed in $\mathrm{m}^{2} \mathrm{eV}^{-1} \mathrm{sr}^{-1}$. These cross sections are presented in tables 5 to 11 and in figures 5 to 11.

\section{CONCLUSIONS}

The angular and energy distributions of electrons ejected from helium atoms by fast protons have been measured. The maximum probable error in the slope against angle, between 0 and $100^{\circ}$ is seven per cent The expected error in the energy distribution is not so well defined, but is estimated to be about 13 per cent in the energy range 15 to $100 \mathrm{eV}$. As the energy falls from 15 to $5 \mathrm{eV}$, the error is estimated to rise to 80 per cent. The distributions have been converted to double differential cross sections by normalising against existing total ionisation cross section data.

\section{ACKNOWLEDGEMENTS}

It is a pleasure for us to acknowledge the support and helpful discussions of Drs A.I.M. Ritchie, J.R. Harries and M.C.E. Petersen and also the assistance of Mr M.R Hyde with construction and experimental work One of us (I.Reid) also wishes to acknowledge receipt of an Australian Institute of Nuclear Science and Engineering research fellowship.

\section{REFERENCES}

De Heer, F.J., Schutten, J., Moustafa, M. [1966] - Ionisation and electron capture cross sections for protons incident on noble and diatomic gases between 10 and $140 \mathrm{keV}$. Physica 32 (11) 1766-1792.

Gibson, D.K., Petersen, M.C.E. [1978] - An apparatus for measuring the energy and angular distribution of electrons ejected in ion-atom collision. AAEC/E448.

Gibson, D.K, Reid, I.D. [1984] - A modified fountain spectrometer for measuring double differential crc sections in ion-atom collisions. J. Phys. E (London), Sci. Instrum., 17 (12) 1227-1230.

Gibson, D.K, Reid, I.D. [1986] - Double differential cross sections for electron ejection from helium by fast protons. J. Phys. B (London), At. Mol. Phys., (in press).

Kim, Y.-K [1975] - Energy distribution of secondary electrons. Radiat. Res., 64 (1) 96-105.

Park, J.T., Schowengerdt, F.D. [1966] - Heavy-particle energy-loss spectrometry inelastic cross sections for proton incident upon helium. Phys. Rev. 185 (1) 152-185.

Rudd, M.E., Toburen, L.H., Stolterfoht, N. [1976] - Differential cross sections for ejection of electrons from helium by protons. At. Data Nucl. Data Tables, 18 (5) 413-432.

Sataka, M., Shirai, A., Kikuchi, A, Nakai [1981] - Ionization cross sections for ion-atom and ion-molecule collisions. JAERI-M 9310.

Solov'ev, E.S., Il'in, R.N., Oparin, V.A., Fedorenko, N.V. [1964] - Sov. Phys. JETP, 18 (2) 342-345. 
TABLE 1

EXAMPLE OF BASIC MEASUREMENT SET

\begin{tabular}{|c|c|c|c|c|c|c|c|c|}
\hline & \multicolumn{4}{|c|}{ He Jet (signal) } & \multicolumn{4}{|c|}{ He Background } \\
\hline Pressure (mPa) & 0.15 & 0.47 & 0.82 & 1.18 & 0.11 & 0.49 & 0.86 & 1.19 \\
\hline Current $\left(10^{-7} \mathrm{~A}\right)$ & 2.31 & 2.30 & 2.29 & 2.28 & 2.31 & 2.30 & 2.29 & 2.28 \\
\hline Time (s) & 31.3 & 31.3 & 31.3 & 31.3 & 31.3 & 31.3 & 31.3 & 31.3 \\
\hline Count & 1690 & 7390 & 12900 & 18800 & 377 & 1630 & 2940 & 4050 \\
\hline Slope & \multicolumn{4}{|c|}{232} & \multicolumn{4}{|c|}{47.6} \\
\hline Variance & \multicolumn{4}{|c|}{2.56} & \multicolumn{4}{|c|}{0.15} \\
\hline
\end{tabular}

The table shows the reduction of eight basic count rate measurements to a cross section measurement for electron energy $30 \mathrm{eV}$, scattering angle $30^{\circ}, \mathrm{H}^{+}$beam energy $50 \mathrm{keV}$. The cross section is given by the difference between the two slopes (185 with variance 2.7$)$. It is in arbitrary units and must still be divided by the electron energy to allow for the proportionality between the analyser energy acceptance and the electron energy.

TABLE 2

EXAMPLE OF RELATIVE NORMALISATION FACTORS

\begin{tabular}{c|l|l}
\hline Detector & Rel.N.F & $\sigma(\%)$ \\
\hline 1 & 1.00 & \\
2 & 1.77 & 2.8 \\
3 & 1.70 & 1.6 \\
4 & 1.04 & 1.7 \\
5 & 0.313 & 1.3 \\
6 & 0.559 & 1.6 \\
7 & 0.700 & 2.1 \\
8 & 1.43 & 3.6 \\
9 & 0.273 & 3.4 \\
\hline
\end{tabular}

\begin{tabular}{ll}
$\left(\Sigma \sigma^{2}\right)^{1 / 2}$ & 6.8 \\
\hline
\end{tabular}

The table shows the normalisation factor of each detector relative to detector 1 (Rel.N.F) and its standard deviation, $\sigma$. The measurement is for $30 \mathrm{eV}$ electrons and $50 \mathrm{keV} \mathrm{H}^{+}$. 
TABLE 3

EXAMPLE OF OPTIMISED RELATIVE NORMALISATION FACTORS v. ELECTRON ENERGY

\begin{tabular}{|c|c|c|c|c|c|c|c|c|c|c|c|}
\hline \multirow{2}{*}{$\begin{array}{l}\text { Energy } \\
(\mathrm{eV})\end{array}$} & \multicolumn{11}{|c|}{ Detectors } \\
\hline & 1 & 2 & 3 & 4 & 5 & 6 & 7 & 8 & 9 & Mean & $\sigma$ \\
\hline 5 & 0.58 & 3.30 & 1.14 & 1.04 & 0.86 & 0.80 & 1.09 & 0.81 & 0.63 & 1.14 & 0.80 \\
\hline 10 & 1.05 & 2.16 & 1.03 & 0.98 & 1.08 & 1.03 & 1.08 & 0.90 & 0.85 & 1.13 & 0.39 \\
\hline 15 & 0.92 & 1.06 & 0.99 & 0.97 & 1.11 & 1.02 & 1.04 & 0.98 & 0.94 & 1.01 & 0.06 \\
\hline 20 & 0.92 & 0.84 & 1.00 & 0.96 & 1.06 & 1.02 & 1.01 & 1.01 & 0.97 & 0.98 & 0.07 \\
\hline 25 & 1.52 & 0.75 & 0.99 & 0.96 & 1.00 & 1.03 & 1.00 & 1.04 & 1.00 & 1.03 & 0.19 \\
\hline 26 & 1.36 & 0.72 & 0.96 & 0.94 & 0.98 & 1.03 & 1.02 & 1.06 & 1.04 & 1.01 & 0.16 \\
\hline 27 & 1.30 & 0.74 & 1.00 & 0.96 & 0.98 & 1.04 & 0.99 & 1.02 & 1.08 & 1.01 & 0.13 \\
\hline 28 & 1.32 & 0.71 & 0.98 & 0.94 & 0.95 & 1.01 & 0.99 & 1.07 & 1.05 & 1.00 & 0.15 \\
\hline 30 & 1.04 & 0.69 & 0.97 & 0.93 & 0.91 & 1.00 & 1.02 & 1.08 & 1.09 & 0.97 & 0.12 \\
\hline 35 & 0.87 & 0.64 & 0.98 & 0.99 & 1.09 & 1.06 & 1.00 & 0.91 & 1.23 & 0.98 & 0.16 \\
\hline 40 & 0.87 & 0.66 & 1.00 & 1.00 & 0.97 & 1.01 & 0.96 & 1.01 & 1.10 & 0.95 & 0.12 \\
\hline 50 & 0.80 & 0.65 & 0.99 & 1.01 & 0.95 & 1.02 & 1.00 & 1.02 & 0.91 & 0.93 & 0.14 \\
\hline 60 & 0.78 & 0.63 & 0.95 & 1.02 & 0.96 & 1.02 & 0.96 & 1.04 & 1.09 & 0.94 & 0.15 \\
\hline 80 & 0.79 & 0.67 & 0.97 & 1.09 & 1.05 & 0.97 & 0.88 & 1.02 & 0.91 & 0.93 & 0.14 \\
\hline$\sigma$ & 0.26 & 0.74 & 0.05 & 0.07 & 0.07 & 0.06 & 0.05 & 0.07 & 0.14 & & \\
\hline Mean & 1.15 & 3.06 & 2.10 & 1.33 & 0.41 & 0.67 & 0.82 & 1.58 & 0.30 & & \\
\hline
\end{tabular}

The table illustrates the scatter in normalisation factors for the nine detectors and 15 energies. The actual normalisation factor applying to any one detector at a particular energy is the product of the mean N.F. for that detector and the appropriate energy-dependent factor for that detector. The scatter of the energy-dependent factors about unity is a measure of the experimental uncertainty.

TABLE 4

TOTAL IONISATION CROSS SECTION

\begin{tabular}{cc}
$\begin{array}{c}\mathbf{H}^{+} \text {energy } \\
(\mathrm{keV})\end{array}$ & $\begin{array}{c}\text { Cross section } \\
10^{-19} \mathrm{~m}^{2}\end{array}$ \\
\hline & \\
20 & 2.4 \\
30 & 4.8 \\
40 & 5.8 \\
50 & 7.9 \\
60 & 8.8 \\
80 & 9.1 \\
100 & 7.7 \\
\hline
\end{tabular}

The total ionisation cross sections are obtained by double integration of the double differential cross sections. 
TABLE 5

CROSS SECTIONS FOR $20 \mathrm{keV} \mathrm{H}^{+}$ON He

\begin{tabular}{cccccccccc}
\hline $\begin{array}{c}\text { Energy } \\
\text { (eV) }\end{array}$ & 0 & 1 & 2 & 3 & \multicolumn{7}{c}{ Angle (degrees) } \\
\hline & & & & & & 5 & 7 & 10 & 20 \\
5 & $9.97-22$ & $7.19-22$ & $6.64-22$ & $6.01-22$ & $5.38-22$ & $4.79-22$ & $3.69-22$ & $2.38-22$ & $6.37-23$ \\
8 & $2.25-21$ & $1.70-21$ & $1.50-21$ & $1.26-21$ & $1.04-21$ & $8.24-22$ & $5.03-22$ & $2.31-22$ & $4.05-23$ \\
10 & $2.71-21$ & $2.00-21$ & $1.44-21$ & $9.50-22$ & $6.11-22$ & $4.00-22$ & $2.18-22$ & $1.22-22$ & $3.07-23$ \\
11 & $5.01-21$ & $2.78-21$ & $1.66-21$ & $9.00-22$ & $4.89-22$ & $2.83-22$ & $1.42-22$ & $9.37-23$ & $2.80-23$ \\
12 & $4.15-21$ & $1.09-21$ & $6.52-22$ & $4.12-22$ & $2.77-22$ & $1.96-22$ & $1.13-22$ & $6.45-23$ & $2.57-23$ \\
13 & $6.19-22$ & $3.69-22$ & $2.94-22$ & $2.34-22$ & $1.91-22$ & $1.57-22$ & $1.10-22$ & $6.98-23$ & $2.44-23$ \\
15 & $1.43-22$ & $1.21-22$ & $1.11-22$ & $1.02-22$ & $9.26-23$ & $8.41-23$ & $6.86-23$ & $5.03-23$ & $2.14-23$ \\
20 & $5.74-23$ & $5.32-23$ & $5.13-23$ & $4.92-23$ & $4.70-23$ & $4.46-23$ & $3.94-23$ & $3.17-23$ & $1.53-23$ \\
25 & $3.50-23$ & $2.99-23$ & $2.85-23$ & $2.77-23$ & $2.71-23$ & $2.65-23$ & $2.48-23$ & $2.14-23$ & $1.12-23$ \\
30 & $2.33-23$ & $1.70-23$ & $1.57-23$ & $1.54-23$ & $1.57-23$ & $1.63-23$ & $1.69-23$ & $1.62-23$ & $8.73-24$ \\
35 & $3.38-23$ & $2.52-23$ & $2.15-23$ & $1.88-23$ & $1.67-23$ & $1.51-23$ & $1.28-23$ & $1.07-23$ & $7.10-24$ \\
40 & $1.23-23$ & $1.15-23$ & $1.11-23$ & $1.07-23$ & $1.04-23$ & $1.01-23$ & $9.26-24$ & $8.15-24$ & $4.92-24$ \\
50 & $7.01-24$ & $6.27-24$ & $5.95-24$ & $5.40-24$ & $4.80-24$ & $4.26-24$ & $3.51-24$ & $2.94-24$ & $1.77-24$ \\
60 & $2.59-24$ & $2.43-24$ & $2.33-24$ & $2.25-24$ & $2.17-24$ & $2.06-24$ & $1.91-24$ & $1.70-24$ & $9.59-25$ \\
80 & $1.41-24$ & $1.30-24$ & $1.15-24$ & $1.03-24$ & $9.19-25$ & $8.26-25$ & $6.73-25$ & $5.08-25$ & $2.31-25$ \\
\hline
\end{tabular}

\begin{tabular}{ccccccccc}
$\begin{array}{c}\text { Energy } \\
(\mathrm{eV})\end{array}$ & 30 & 40 & 50 & 60 & 70 & 80 & 90 & 100 \\
\hline & & & & & & & & \\
5 & $2.94-23$ & $1.63-23$ & $1.05-23$ & $8.42-24$ & $6.09-24$ & $5.66-24$ & $5.47-24$ & $6.28-24$ \\
8 & $2.00-23$ & $1.18-23$ & $7.99-24$ & $6.04-24$ & $4.43-24$ & $4.10-24$ & $3.54-24$ & $3.65-24$ \\
10 & $1.69-23$ & $9.88-24$ & $6.32-24$ & $4.56-24$ & $3.36-24$ & $2.81-24$ & $2.68-24$ & $2.91-24$ \\
11 & $1.54-23$ & $9.02-24$ & $5.79-24$ & $4.24-24$ & $3.08-24$ & $2.86-24$ & $2.19-24$ & $2.34-24$ \\
12 & $1.38-23$ & $8.09-24$ & $5.35-24$ & $3.87-24$ & $2.98-24$ & $2.57-24$ & $2.36-24$ & $2.68-24$ \\
13 & $1.29-23$ & $7.83-24$ & $4.84-24$ & $3.15-24$ & $2.38-24$ & $2.03-24$ & $1.90-24$ & $1.91-24$ \\
15 & $1.13-23$ & $6.54-24$ & $4.00-24$ & $2.85-24$ & $2.15-24$ & $1.80-24$ & $1.74-24$ & $1.85-24$ \\
20 & $7.83-24$ & $4.24-24$ & $2.44-24$ & $1.70-24$ & $1.21-24$ & $1.11-24$ & $8.61-25$ & $9.21-25$ \\
25 & $5.71-24$ & $2.92-24$ & $1.64-24$ & $1.07-24$ & $8.05-25$ & $6.88-25$ & $6.56-25$ & $6.82-25$ \\
30 & $4.24-24$ & $2.36-24$ & $1.48-24$ & $9.88-25$ & $7.17-25$ & $6.09-25$ & $5.88-25$ & $5.88-25$ \\
35 & $4.43-24$ & $2.52-24$ & $1.54-24$ & $1.12-24$ & $8.82-25$ & $7.68-25$ & $7.75-25$ & $8.45-25$ \\
40 & $2.68-24$ & $1.42-24$ & $7.86-25$ & $5.01-25$ & $3.69-25$ & $2.96-25$ & $2.09-25$ & $2.04-25$ \\
50 & $9.35-25$ & $5.26-25$ & $3.38-25$ & $2.30-25$ & $1.74-25$ & $1.51-25$ & $1.48-25$ & $1.47-25$ \\
60 & $4.68-25$ & $2.37-25$ & $1.41-25$ & $9.88-26$ & $8.07-26$ & $7.22-26$ & $7.07-26$ & $7.91-26$ \\
80 & $1.22-25$ & $6.95-26$ & $4.49-26$ & $3.31-26$ & $2.67-26$ & $2.24-26$ & $2.12-26$ & $2.65-26$ \\
\hline
\end{tabular}

Double differential cross sections for electrons ejected from $\mathrm{He}$ by $20 \mathrm{keV} \mathrm{H^{+ }}$ in $\mathrm{m}^{2} \mathrm{eV}^{-1} \mathrm{sr}^{-1}$ 
TABLE 6

CROSS SECTIONSS FOR $30 \mathrm{keV} \mathrm{H}^{+}$ON He

\begin{tabular}{|c|c|c|c|c|c|c|c|c|c|}
\hline \multirow{2}{*}{$\begin{array}{l}\text { Energy } \\
(\mathrm{eV})\end{array}$} & \multicolumn{9}{|c|}{ Angle (degrees) } \\
\hline & 0 & 1 & 2 & 3 & 4 & 5 & 7 & 10 & 20 \\
\hline 5 & $1.76-21$ & $1.26-21$ & $1.20-21$ & $1.12-21$ & $1.03-21$ & $9.34-22$ & $7.39-22$ & $4.87-22$ & $1.05-22$ \\
\hline 10 & $2.04-21$ & $1.90-21$ & $1.74-21$ & $1.56-21$ & $1.39-21$ & $1.21-21$ & $8.82-22$ & $5.27-22$ & $1.00-22$ \\
\hline 15 & $5.39-21$ & $3.14-21$ & $1.93-21$ & $1.24-21$ & $8.40-22$ & $5.95-22$ & $3.35-22$ & $1.82-22$ & $5.95-23$ \\
\hline 16 & $7.53-21$ & $3.07-21$ & $1.77-21$ & $1.10-21$ & $7.22-22$ & $4.98-22$ & $2.76-22$ & $1.54-22$ & $5.79-23$ \\
\hline 17 & $4.84-21$ & $9.18-22$ & $6.68-22$ & $5.03-22$ & $3.90-22$ & $3.10-22$ & $2.09-22$ & $1.34-22$ & $5.32-23$ \\
\hline 18 & $1.30-21$ & $5.95-22$ & $4.66-22$ & $3.74-22$ & $3.05-22$ & $2.51-22$ & $1.82-22$ & $1.24-22$ & $5.09-23$ \\
\hline 20 & $3.74-22$ & $3.16-22$ & $2.67-22$ & $2.34-22$ & $2.02-22$ & $1.77-22$ & $1.40-22$ & $1.02-22$ & $4.45-23$ \\
\hline 25 & $1.23-22$ & $1.05-22$ & $1.05-22$ & $1.04-22$ & $1.02-22$ & $9.83-23$ & $9.00-23$ & $7.47-23$ & $3.56-23$ \\
\hline 30 & $9.09-23$ & $7.96-23$ & $7.87-23$ & $7.72-23$ & $7.51-23$ & $7.25-23$ & $6.66-23$ & $5.67-23$ & $2.87-23$ \\
\hline 35 & $8.42-23$ & $6.54-23$ & $6.38-23$ & $6.19-23$ & $5.94-23$ & $5.67-23$ & $5.23-23$ & $4.38-23$ & $2.57-23$ \\
\hline 40 & $4.80-23$ & $4.48-23$ & $4.38-23$ & $4.26-23$ & $4.15-23$ & $3.99-23$ & $3.74-23$ & $3.28-23$ & $1.88-23$ \\
\hline 50 & $2.49-23$ & $2.40-23$ & $2.29-23$ & $2.24-23$ & $2.15-23$ & $2.06-23$ & $1.91-23$ & $1.68-23$ & $9.73-24$ \\
\hline 60 & $1.21-23$ & $1.16-23$ & $1.14-23$ & $1.12-23$ & $1.10-23$ & $1.07-23$ & $1.01-23$ & $9.04-24$ & $5.36-24$ \\
\hline 80 & $4.26-24$ & $4.06-24$ & $3.84-24$ & $3.67-24$ & $3.50-24$ & $3.37-24$ & $3.08-24$ & $2.71-24$ & $1.57-24$ \\
\hline 100 & $1.39-24$ & $1.24-24$ & $1.21-24$ & $1.17-24$ & $1.13-24$ & $1.08-24$ & $9.89-25$ & $8.48-25$ & $4.50-25$ \\
\hline \multirow{2}{*}{$\begin{array}{c}\text { Energy } \\
(\mathrm{eV})\end{array}$} & \multicolumn{9}{|c|}{ Angle (degrees) } \\
\hline & 30 & 40 & 50 & 60 & 70 & 80 & 90 & 100 & \\
\hline 5 & $4.18-23$ & $2.27-23$ & $1.20-23$ & $6.84-24$ & $4.96-24$ & $4.75-24$ & $4.06-24$ & $3.12-24$ & \\
\hline 10 & $3.75-23$ & $1.81-23$ & $9.62-24$ & $5.52-24$ & $3.75-24$ & $3.41-24$ & $2.76-24$ & $2.29-24$ & \\
\hline 15 & $2.87-23$ & $1.48-23$ & $7.62-24$ & $4.17-24$ & $2.62-24$ & $2.09-24$ & $1.59-24$ & $1.29-24$ & \\
\hline 16 & $2.83-23$ & $1.38-23$ & $7.22-24$ & $3.88-24$ & $2.62-24$ & $2.06-24$ & $1.55-24$ & $1.29-24$ & \\
\hline 17 & $2.64-23$ & $1.35-23$ & $6.84-24$ & $3.70-24$ & $2.34-24$ & $1.86-24$ & $1.46-24$ & $1.19-24$ & \\
\hline 18 & $2.51-23$ & $1.26-23$ & $6.13-24$ & $3.25-24$ & $2.04-24$ & $1.53-24$ & $1.13-24$ & $9.16-25$ & \\
\hline 20 & $2.22-23$ & $1.14-23$ & $5.61-24$ & $2.92-24$ & $1.82-24$ & $1.41-24$ & $1.11-24$ & $9.22-25$ & \\
\hline 25 & $1.79-23$ & $8.14-24$ & $3.95-24$ & $2.07-24$ & $1.35-24$ & $1.06-24$ & $8.01-25$ & $6.28-25$ & \\
\hline 30 & $1.40-23$ & $6.42-24$ & $2.94-24$ & $1.53-24$ & $9.80-25$ & $7.00-25$ & $5.25-25$ & $4.06-25$ & \\
\hline 35 & $1.45-23$ & $6.64-24$ & $2.87-24$ & $1.65-24$ & $1.44-24$ & $1.40-24$ & $1.10-24$ & $1.00-24$ & \\
\hline 40 & $9.22-24$ & 4.18-24 & $1.93-24$ & $1.03-24$ & $6.62-25$ & $5.36-25$ & $4.57-25$ & $3.70-25$ & \\
\hline 50 & $4.91-24$ & $2.11-24$ & $9.60-25$ & $5.09-25$ & $3.12-25$ & $2.36-25$ & $1.68-25$ & $1.32-25$ & \\
\hline 60 & $2.51-24$ & $1.10-24$ & $5.02-25$ & $2.67-25$ & $1.76-25$ & $1.44-25$ & $1.07-25$ & $8.43-26$ & \\
\hline 80 & $7.14-25$ & $3.14-25$ & $1.49-25$ & $8.24-26$ & $5.54-26$ & $4.33-26$ & $2.48-26$ & $1.97-26$ & \\
\hline 100 & $2.25-25$ & $9.67-26$ & $5.86-26$ & $4.09-26$ & $2.55-26$ & $2.22-26$ & $1.36-26$ & $6.79-27$ & \\
\hline
\end{tabular}

Double differential cross sections for electrons ejected from $\mathrm{He}$ by $30 \mathrm{keV} \mathrm{H} \mathrm{H}^{+}$in $\mathrm{m}^{2} \mathrm{eV}^{-1} \mathrm{sr}^{-1}$ 
TABLE 7

CROSS SECTIONS FOR $40 \mathrm{keV} \mathrm{H}{ }^{+}$ON He

\begin{tabular}{|c|c|c|c|c|c|c|c|c|c|}
\hline \multirow{2}{*}{$\begin{array}{l}\text { Energy } \\
(\mathrm{eV})\end{array}$} & \multicolumn{9}{|c|}{ Angle (degrees) } \\
\hline & 0 & 1 & 2 & 3 & 4 & 5 & 7 & 10 & 20 \\
\hline 5 & $4.89-22$ & $3.15-22$ & $2.97-22$ & $2.80-22$ & $2.65-22$ & $2.48-22$ & $2.22-22$ & $1.85-22$ & $9.18-23$ \\
\hline 10 & $1.56-21$ & $1.18-21$ & $1.16-21$ & $1.11-21$ & $1.04-21$ & $9.63-22$ & $7.95-22$ & $5.47-22$ & $1.29-22$ \\
\hline 15 & $2.08-21$ & $1.73-21$ & $1.59-21$ & $1.41-21$ & $1.24-21$ & $1.08-21$ & $7.86-22$ & $4.59-22$ & $9.48-23$ \\
\hline 20 & $5.95-21$ & $3.55-21$ & $2.20-21$ & $1.44-21$ & $9.79-22$ & $6.93-22$ & $3.85-22$ & $2.02-22$ & $6.30-23$ \\
\hline 21 & $6.69-21$ & $3.68-21$ & $2.19-21$ & $1.37-21$ & $9.05-22$ & $6.28-22$ & $3.47-22$ & $1.84-22$ & $6.35-23$ \\
\hline 22 & $6.99-21$ & $1.49-21$ & $1.02-21$ & $7.25-22$ & $5.36-22$ & $4.09-22$ & $2.56-22$ & $1.55-22$ & $5.79-23$ \\
\hline 25 & $3.68-22$ & $2.73-22$ & $2.54-22$ & $2.32-22$ & $2.13-22$ & $1.95-22$ & $1.63-22$ & $1.21-22$ & $5.03-23$ \\
\hline 30 & $1.62-22$ & $1.47-22$ & $1.39-22$ & $1.31-22$ & $1.24-22$ & $1.16-22$ & $1.00-22$ & $7.92-23$ & $3.79-23$ \\
\hline 35 & $1.24-22$ & $1.08-22$ & $1.07-22$ & $1.04-22$ & $1.01-22$ & $9.55-23$ & $8.55-23$ & $7.04-23$ & $3.67-23$ \\
\hline 40 & $7.24-23$ & $6.66-23$ & $6.53-23$ & $6.43-23$ & $6.25-23$ & $6.05-23$ & $5.60-23$ & $4.87-23$ & $2.73-23$ \\
\hline 50 & $4.60-23$ & $4.37-23$ & $4.27-23$ & $4.17-23$ & $4.04-23$ & $3.95-23$ & $3.64-23$ & $3.18-23$ & $1.85-23$ \\
\hline 60 & $2.69-23$ & $2.48-23$ & $2.46-23$ & $2.41-23$ & $2.39-23$ & $2.33-23$ & $2.18-23$ & $1.92-23$ & $1.14-23$ \\
\hline 80 & $9.76-24$ & $9.04-24$ & $8.85-24$ & $8.59-24$ & $8.33-24$ & $8.10-24$ & $7.58-24$ & $6.80-24$ & 4.13-24 \\
\hline 100 & $3.61-24$ & $3.38-24$ & $3.29-24$ & $3.26-24$ & $3.15-24$ & $3.07-24$ & $2.87-24$ & $2.50-24$ & $1.42-24$ \\
\hline \multirow{2}{*}{$\begin{array}{c}\text { Energy } \\
(\mathrm{eV})\end{array}$} & \multicolumn{9}{|c|}{ Angle (degrees) } \\
\hline & 30 & 40 & 50 & 60 & 70 & 80 & 90 & 100 & \\
\hline 5 & $4.20-23$ & $2.19-23$ & $1.21-23$ & $7.39-24$ & $4.84-24$ & $3.46-24$ & $2.44-24$ & $2.11-24$ & \\
\hline 10 & $4.63-23$ & $2.22-23$ & $1.18-23$ & $6.93-24$ & $4.42-24$ & $2.87-24$ & $2.12-24$ & $1.71-24$ & \\
\hline 15 & $3.71-23$ & $1.85-23$ & $9.32-24$ & $5.10-24$ & $3.04-24$ & $1.97-24$ & $1.56-24$ & $1.29-24$ & \\
\hline 20 & $2.93-23$ & $1.57-23$ & $7.92-24$ & $4.04-24$ & $2.32-24$ & $1.42-24$ & $1.07-24$ & $9.73-25$ & \\
\hline 21 & $2.93-23$ & $1.48-23$ & $7.22-24$ & $3.68-24$ & $2.20-24$ & $1.45-24$ & $1.14-24$ & $9.93-25$ & \\
\hline 22 & $2.69-23$ & $1.45-23$ & $7.20-24$ & $3.72-24$ & $2.12-24$ & $1.35-24$ & $9.23-25$ & $8.77-25$ & \\
\hline 25 & $2.33-23$ & $1.24-23$ & $6.05-24$ & $3.01-24$ & $1.66-24$ & $1.06-24$ & $7.32-25$ & $6.44-25$ & \\
\hline 30 & $1.81-23$ & $1.02-23$ & $4.84-24$ & $2.34-24$ & $1.27-24$ & $7.85-25$ & $5.65-25$ & $4.60-25$ & \\
\hline 35 & $2.01-23$ & $1.05-23$ & $4.80-24$ & $2.33-24$ & $1.31-24$ & $8.55-25$ & $6.64-25$ & $5.74-25$ & \\
\hline 40 & $1.35-23$ & $6.73-24$ & $3.04-24$ & $1.48-24$ & $8.44-25$ & $5.77-25$ & $4.09-25$ & $3.35-25$ & \\
\hline 50 & $8.97-24$ & $3.88-24$ & $1.67-24$ & $7.88-25$ & $4.44-25$ & $2.93-25$ & $2.30-25$ & $1.85-25$ & \\
\hline 60 & $5.45-24$ & $2.39-24$ & $1.01-24$ & $4.81-25$ & $2.80-25$ & $1.87-25$ & $1.39-25$ & $1.22-25$ & \\
\hline 80 & $1.95-24$ & $8.42-25$ & $3.50-25$ & $1.70-25$ & $1.08-25$ & $7.41-26$ & $6.21-26$ & $4.88-26$ & \\
\hline 100 & $7.01-25$ & $2.87-25$ & $1: 20-25$ & $6.79-26$ & 4.34-26 & $3.10-26$ & $2.23-26$ & $2.01-26$ & \\
\hline
\end{tabular}

Double differential cross sections for electrons ejected from $\mathrm{He}$ by $40 \mathrm{keV} \mathrm{\textrm {H } ^ { + }}$ in $\mathrm{m}^{2} \mathrm{eV}^{-1} \mathrm{sr}^{-1}$ 
TABLE 8

CROSS SECTIONS FOR $50 \mathrm{keV} \mathrm{H}^{+}$, ON He

\begin{tabular}{cccccccccc}
\hline $\begin{array}{c}\text { Energy } \\
(\mathrm{eV})\end{array}$ & 0 & 1 & 2 & 3 & 4 & 5 & 7 & 10 & 20 \\
\hline & & & & & & & & & \\
5 & $4.51-22$ & $4.21-22$ & $3.96-22$ & $3.70-22$ & $3.47-22$ & $3.23-22$ & $2.85-22$ & $2.34-22$ & $1.22-22$ \\
10 & $1.29-21$ & $1.16-21$ & $1.05-21$ & $9.46-22$ & $8.55-22$ & $7.72-22$ & $6.31-22$ & $4.67-22$ & $1.69-22$ \\
15 & $1.50-21$ & $1.34-21$ & $1.19-21$ & $1.06-21$ & $9.40-22$ & $8.37-22$ & $6.60-22$ & $4.67-22$ & $1.44-22$ \\
20 & $1.28-21$ & $1.13-21$ & $1.00-21$ & $8.86-22$ & $7.85-22$ & $6.96-22$ & $5.47-22$ & $3.80-22$ & $1.13-22$ \\
25 & $2.96-21$ & $2.08-21$ & $1.51-21$ & $1.12-21$ & $8.55-22$ & $6.65-22$ & $4.28-22$ & $2.49-22$ & $8.39-23$ \\
26 & $4.90-21$ & $2.98-21$ & $1.91-21$ & $1.27-21$ & $8.89-22$ & $6.47-22$ & $3.82-22$ & $2.16-22$ & $7.98-23$ \\
27 & $6.03-21$ & $3.31-21$ & $2.01-21$ & $1.27-21$ & $8.57-22$ & $6.02-22$ & $3.41-22$ & $1.93-22$ & $7.60-23$ \\
28 & $7.48-21$ & $2.72-21$ & $1.63-21$ & $1.04-21$ & $7.06-22$ & $5.04-22$ & $2.96-22$ & $1.74-22$ & $7.34-23$ \\
30 & $1.44-21$ & $7.80-22$ & $5.91-22$ & $4.61-22$ & $3.67-22$ & $3.01-22$ & $2.15-22$ & $1.47-22$ & $6.49-23$ \\
35 & $2.57-22$ & $2.29-22$ & $2.05-22$ & $1.82-22$ & $1.66-22$ & $1.49-22$ & $1.25-22$ & $9.81-23$ & $4.68-23$ \\
40 & $1.53-22$ & $1.42-22$ & $1.32-22$ & $1.24-22$ & $1.15-22$ & $1.08-22$ & $9.47-23$ & $7.86-23$ & $4.24-23$ \\
50 & $7.47-23$ & $7.12-23$ & $6.81-23$ & $6.54-23$ & $6.23-23$ & $5.98-23$ & $5.52-23$ & $4.82-23$ & $2.87-23$ \\
60 & $4.99-23$ & $4.70-23$ & $4.47-23$ & $4.24-23$ & $4.04-23$ & $3.88-23$ & $3.56-23$ & $3.15-23$ & $1.98-23$ \\
80 & $2.21-23$ & $2.11-23$ & $2.03-23$ & $1.93-23$ & $1.85-23$ & $1.79-23$ & $1.66-23$ & $1.49-23$ & $9.19-24$ \\
100 & $1.16-23$ & $1.07-23$ & $1.01-23$ & $9.58-24$ & $9.09-24$ & $8.65-24$ & $7.88-24$ & $6.85-24$ & $4.09-24$ \\
\hline
\end{tabular}

\begin{tabular}{ccccccccc} 
Energy & & \multicolumn{8}{c}{ Angle (degrees) } \\
$(\mathrm{eV})$ & 30 & 40 & 50 & 60 & 70 & 80 & 90 & 100 \\
\hline & & & & & & & & \\
5 & $5.98-23$ & $2.96-23$ & $1.50-23$ & $8.86-24$ & $6.00-24$ & $4.11-24$ & $2.67-24$ & $2.37-24$ \\
10 & $6.80-23$ & $3.05-23$ & $1.53-23$ & $8.39-24$ & $5.06-24$ & $3.18-24$ & $2.15-24$ & $1.84-24$ \\
15 & $5.68-23$ & $2.60-23$ & $1.30-23$ & $6.78-24$ & $3.85-24$ & $2.36-24$ & $1.62-24$ & $1.28-24$ \\
20 & $4.59-23$ & $2.13-23$ & $1.04-23$ & $5.21-24$ & $2.82-24$ & $1.72-24$ & $1.14-24$ & $8.98-25$ \\
25 & $3.68-23$ & $1.75-23$ & $8.55-24$ & $4.13-24$ & $2.18-24$ & $1.29-24$ & $8.65-25$ & $6.78-25$ \\
26 & $3.56-23$ & $1.72-23$ & $8.50-24$ & $4.09-24$ & $2.11-24$ & $1.30-24$ & $8.96-25$ & $6.93-25$ \\
27 & $3.41-23$ & $1.64-23$ & $7.95-24$ & $3.78-24$ & $1.96-24$ & $1.14-24$ & $8.16-25$ & $6.29-25$ \\
28 & $3.34-23$ & $1.60-23$ & $7.63-24$ & $3.56-24$ & $1.87-24$ & $1.15-24$ & $7.80-25$ & $5.98-25$ \\
30 & $3.05-23$ & $1.45-23$ & $6.90-24$ & $3.20-24$ & $1.69-24$ & $1.02-24$ & $7.11-25$ & $5.50-25$ \\
35 & $2.77-23$ & $1.53-23$ & $7.19-24$ & $3.37-24$ & $1.80-24$ & $1.10-24$ & $7.72-25$ & $6.13-25$ \\
40 & $2.16-23$ & $1.04-23$ & $4.75-24$ & $2.13-24$ & $1.10-24$ & $6.76-25$ & $4.68-25$ & $3.73-25$ \\
50 & $1.47-23$ & $6.81-24$ & $2.95-24$ & $1.25-24$ & $6.21-25$ & $3.98-25$ & $2.18-25$ & $1.98-25$ \\
60 & $1.01-23$ & $4.51-24$ & $1.85-24$ & $7.96-25$ & $4.11-25$ & $2.52-25$ & $1.72-25$ & $1.37-25$ \\
80 & $4.39-24$ & $1.84-24$ & $7.26-25$ & $3.10-25$ & $1.62-25$ & $9.68-26$ & $6.11-26$ & $5.57-26$ \\
100 & $1.85-24$ & $7.40-25$ & $2.80-25$ & $1.23-25$ & $6.81-26$ & $4.83-26$ & $3.62-26$ & $2.80-26$ \\
\hline
\end{tabular}

Double differential cross sections for electrons ejected from $\mathrm{He}$ by $50 \mathrm{keV} \mathrm{H}^{+}$in $\mathrm{m}^{2} \mathrm{eV}^{-1} \mathrm{sr}^{-1}$ 
TABLE 9

\section{CROSS SECTIONS FOR $60 \mathrm{keV} \mathrm{H}^{+}$ON He}

\begin{tabular}{cccccccccc}
\hline $\begin{array}{c}\text { Energy } \\
(\mathrm{eV})\end{array}$ & 0 & 1 & 2 & 3 & 4 & 5 & 7 & 10 & 20 \\
\hline & & & & & & & & & \\
& & & & & & & & \\
5 & $2.94-22$ & $2.81-22$ & $2.72-22$ & $2.59-22$ & $2.50-22$ & $2.39-22$ & $2.20-22$ & $1.94-22$ & $1.28-22$ \\
10 & $7.64-22$ & $7.10-22$ & $6.57-22$ & $6.09-22$ & $5.64-22$ & $5.24-22$ & $4.50-22$ & $3.57-22$ & $1.67-22$ \\
15 & $7.09-22$ & $6.53-22$ & $6.05-22$ & $5.59-22$ & $5.12-22$ & $4.74-22$ & $4.03-22$ & $3.14-22$ & $1.40-22$ \\
20 & $8.57-22$ & $7.62-22$ & $6.81-22$ & $6.07-22$ & $5.44-22$ & $4.87-22$ & $3.92-22$ & $2.87-22$ & $1.10-22$ \\
25 & $1.20-21$ & $1.02-21$ & $8.66-22$ & $7.44-22$ & $6.36-22$ & $5.46-22$ & $4.09-22$ & $2.72-22$ & $8.75-23$ \\
30 & $2.63-21$ & $1.91-21$ & $1.41-21$ & $1.05-21$ & $7.97-22$ & $6.14-22$ & $3.87-22$ & $2.15-22$ & $6.42-23$ \\
32 & $3.88-21$ & $2.24-21$ & $1.48-21$ & $1.02-21$ & $7.25-22$ & $5.33-22$ & $3.14-22$ & $1.74-22$ & $5.88-23$ \\
33 & $4.70-21$ & $1.82-21$ & $1.22-21$ & $8.49-22$ & $6.14-22$ & $4.59-22$ & $2.79-22$ & $1.60-22$ & $5.73-23$ \\
35 & $1.47-21$ & $6.49-22$ & $4.90-22$ & $3.81-22$ & $3.03-22$ & $2.48-22$ & $1.74-22$ & $1.13-22$ & $4.68-23$ \\
40 & $2.18-22$ & $2.00-22$ & $1.87-22$ & $1.71-22$ & $1.57-22$ & $1.44-22$ & $1.22-22$ & $9.29-23$ & $4.33-23$ \\
50 & $7.92-23$ & $7.71-23$ & $7.60-23$ & $7.46-23$ & $7.20-23$ & $6.97-23$ & $6.40-23$ & $5.44-23$ & $3.00-23$ \\
60 & $4.72-23$ & $4.57-23$ & $4.57-23$ & $4.51-23$ & $4.42-23$ & $4.35-23$ & $4.11-23$ & $3.66-23$ & $2.16-23$ \\
80 & $2.16-23$ & $2.15-23$ & $2.16-23$ & $2.18-23$ & $2.18-23$ & $2.16-23$ & $2.11-23$ & $1.91-23$ & $1.18-23$ \\
100 & $1.51-23$ & $1.48-23$ & $1.46-23$ & $1.43-23$ & $1.39-23$ & $1.36-23$ & $1.27-23$ & $1.14-23$ & $6.88-24$ \\
\hline
\end{tabular}

\begin{tabular}{ccccccccc} 
Energy & \multicolumn{8}{c}{ Angle (degrees) } \\
$(\mathrm{eV})$ & 30 & 40 & 50 & 60 & 70 & 80 & 90 & 100 \\
\hline & & & & & & & & \\
5 & $8.45-23$ & $5.35-23$ & $3.16-23$ & $2.09-23$ & $1.39-23$ & $8.07-24$ & $5.75-24$ & $4.77-24$ \\
10 & $7.75-23$ & $4.13-23$ & $2.28-23$ & $1.35-23$ & $8.21-24$ & $5.07-24$ & $3.35-24$ & $2.76-24$ \\
15 & $6.23-23$ & $3.24-23$ & $1.78-23$ & $9.90-24$ & $5.68-24$ & $3.42-24$ & $2.20-24$ & $1.82-24$ \\
20 & $4.92-23$ & $2.52-23$ & $1.35-23$ & $7.33-24$ & $3.92-24$ & $2.02-24$ & $1.26-24$ & $9.36-25$ \\
25 & $4.03-23$ & $2.07-23$ & $1.09-23$ & $5.68-24$ & $2.96-24$ & $1.54-24$ & $9.38-25$ & $7.55-25$ \\
30 & $3.22-23$ & $1.70-23$ & $9.05-24$ & $4.74-24$ & $2.41-24$ & $1.32-24$ & $8.40-25$ & $6.97-25$ \\
32 & $3.00-23$ & $1.63-23$ & $9.08-24$ & $4.83-24$ & $2.61-24$ & $1.59-24$ & $1.12-24$ & $8.97-25$ \\
33 & $3.05-23$ & $1.65-23$ & $8.42-24$ & $4.50-24$ & $2.46-24$ & $1.47-24$ & $1.06-24$ & $8.36-25$ \\
35 & $2.90-23$ & $1.75-23$ & $9.19-24$ & $4.66-24$ & $2.39-24$ & $1.31-24$ & $8.75-25$ & $7.27-25$ \\
40 & $2.29-23$ & $1.23-23$ & $6.35-24$ & $3.14-24$ & $1.60-24$ & $8.45-25$ & $5.37-25$ & $4.18-25$ \\
50 & $1.65-23$ & $8.82-24$ & $4.33-24$ & $2.02-24$ & $9.86-25$ & $5.46-25$ & $3.35-25$ & $2.72-25$ \\
60 & $1.20-23$ & $6.12-24$ & $2.78-24$ & $1.21-24$ & $5.77-25$ & $3.29-25$ & $2.00-25$ & $1.68-25$ \\
80 & $6.22-24$ & $2.92-24$ & $1.22-24$ & $5.05-25$ & $2.48-25$ & $1.45-25$ & $1.06-25$ & $7.42-26$ \\
100 & $3.39-24$ & $1.48-24$ & $5.86-25$ & $2.57-25$ & $1.39-25$ & $9.16-26$ & $8.12-26$ & $7.34-26$ \\
\hline
\end{tabular}

Double differential cross sections for electrons ejected from $\mathrm{He}$ by $60 \mathrm{keV} \mathrm{H^{+ }}$ in $\mathrm{m}^{2} \mathrm{eV}^{-1} \mathrm{sr}^{-1}$ 
TABLE 10

CROSS SECTIONS FOR $80 \mathrm{keV} \mathrm{H}^{+}$ON He

\begin{tabular}{cccccccccc}
\hline $\begin{array}{c}\text { Energy } \\
\text { (eV) }\end{array}$ & 0 & 1 & 2 & 3 & 4 & 5 & 7 & 10 & 20 \\
\hline & & & & & & & & & \\
& & & & & \multicolumn{7}{c}{ Angle (degrees) } \\
5 & $5.05-22$ & $4.74-22$ & $4.45-22$ & $4.20-22$ & $3.95-22$ & $3.70-22$ & $3.28-22$ & $2.73-22$ & $1.47-22$ \\
10 & $4.59-22$ & $4.33-22$ & $4.04-22$ & $3.80-22$ & $3.55-22$ & $3.33-22$ & $2.94-22$ & $2.41-22$ & $1.27-22$ \\
15 & $4.08-22$ & $3.83-22$ & $3.60-22$ & $3.37-22$ & $3.16-22$ & $2.96-22$ & $2.59-22$ & $2.13-22$ & $1.11-22$ \\
20 & $5.18-22$ & $4.79-22$ & $4.41-22$ & $4.04-22$ & $3.74-22$ & $3.44-22$ & $2.91-22$ & $2.27-22$ & $9.79-23$ \\
25 & $5.53-22$ & $5.27-22$ & $5.12-22$ & $4.93-22$ & $4.68-22$ & $4.38-22$ & $3.69-22$ & $2.68-22$ & $8.62-23$ \\
30 & $7.40-22$ & $5.66-22$ & $5.40-22$ & $5.07-22$ & $4.68-22$ & $4.27-22$ & $3.47-22$ & $2.39-22$ & $7.20-23$ \\
35 & $1.07-21$ & $7.81-22$ & $6.99-22$ & $6.19-22$ & $5.48-22$ & $4.81-22$ & $3.63-22$ & $2.36-22$ & $6.49-23$ \\
40 & $1.52-21$ & $1.07-21$ & $7.70-22$ & $5.76-22$ & $4.40-22$ & $3.48-22$ & $2.31-22$ & $1.42-22$ & $4.92-23$ \\
42 & $1.58-21$ & $1.06-21$ & $7.40-22$ & $5.34-22$ & $4.01-22$ & $3.10-22$ & $2.02-22$ & $1.26-22$ & $4.64-23$ \\
44 & $3.03-21$ & $1.30-21$ & $8.23-22$ & $5.50-22$ & $3.88-22$ & $2.87-22$ & $1.77-22$ & $1.09-22$ & $4.33-23$ \\
45 & $2.50-21$ & $5.80-22$ & $4.31-22$ & $3.33-22$ & $2.64-22$ & $2.15-22$ & $1.50-22$ & $1.01-22$ & $4.08-23$ \\
50 & $2.48-22$ & $2.00-22$ & $1.77-22$ & $1.56-22$ & $1.38-22$ & $1.23-22$ & $9.98-23$ & $7.46-23$ & $3.44-23$ \\
60 & $8.37-23$ & $7.20-23$ & $6.92-23$ & $6.63-23$ & $6.33-23$ & $6.01-23$ & $5.39-23$ & $4.47-23$ & $2.46-23$ \\
80 & $3.70-23$ & $3.30-23$ & $3.19-23$ & $3.05-23$ & $2.94-23$ & $2.80-23$ & $2.59-23$ & $2.25-23$ & $1.42-23$ \\
100 & $1.68-23$ & $1.67-23$ & $1.65-23$ & $1.63-23$ & $1.59-23$ & $1.56-23$ & $1.46-23$ & $1.32-23$ & $8.60-24$ \\
\hline
\end{tabular}

\begin{tabular}{ccccccccc}
\multirow{2}{*}{$\begin{array}{c}\text { Energy } \\
\text { (eV) }\end{array}$} & 30 & 40 & 50 & 60 & 70 & 80 & 90 & 100 \\
\hline & & & & & & & & \\
5 & $9.43-23$ & $5.92-23$ & $3.58-23$ & $2.33-23$ & $1.61-23$ & $1.08-23$ & $7.73-24$ & $6.36-24$ \\
10 & $7.20-23$ & $4.13-23$ & $2.36-23$ & $1.32-23$ & $7.48-24$ & $4.47-24$ & $3.12-24$ & $2.18-24$ \\
15 & $5.98-23$ & $3.30-23$ & $1.90-23$ & $1.08-23$ & $6.05-24$ & $3.30-24$ & $1.95-24$ & $1.61-24$ \\
20 & $4.82-23$ & $2.54-23$ & $1.41-23$ & $7.78-24$ & $4.22-24$ & $2.06-24$ & $1.22-24$ & $9.59-25$ \\
25 & $3.92-23$ & $2.06-23$ & $1.15-23$ & $6.29-24$ & $3.32-24$ & $1.74-24$ & $1.06-24$ & $7.27-25$ \\
30 & $3.22-23$ & $1.70-23$ & $9.38-24$ & $5.04-24$ & $2.56-24$ & $1.31-24$ & $7.61-25$ & $5.60-25$ \\
35 & $3.02-23$ & $1.61-23$ & $8.44-24$ & $4.43-24$ & $2.27-24$ & $1.35-24$ & $1.02-24$ & $7.05-25$ \\
40 & $2.39-23$ & $1.30-23$ & $7.20-24$ & $3.67-24$ & $1.75-24$ & $8.19-25$ & $4.81-25$ & $4.04-25$ \\
42 & $2.25-23$ & $1.22-23$ & $6.77-24$ & $3.39-24$ & $1.57-24$ & $8.03-25$ & $4.59-25$ & $4.75-25$ \\
44 & $2.16-23$ & $1.16-23$ & $6.36-24$ & $3.17-24$ & $1.49-24$ & $7.91-25$ & $4.36-25$ & $3.69-25$ \\
45 & $2.06-23$ & $1.10-23$ & $5.80-24$ & $2.84-24$ & $1.29-24$ & $5.91-25$ & $3.44-25$ & $3.09-25$ \\
50 & $1.79-23$ & $9.47-24$ & $4.89-24$ & $2.43-24$ & $1.13-24$ & $4.20-25$ & $2.71-25$ & $1.88-25$ \\
60 & $1.37-23$ & $7.20-24$ & $3.50-24$ & $1.56-24$ & $6.58-25$ & $3.51-25$ & $2.13-25$ & $1.83-25$ \\
80 & $7.99-24$ & $3.93-24$ & $1.75-24$ & $7.59-25$ & $3.37-25$ & $1.80-25$ & $1.23-25$ & $1.03-25$ \\
100 & $4.68-24$ & $2.13-24$ & $8.55-25$ & $3.88-25$ & $2.04-25$ & $1.05-25$ & $8.28-26$ & $8.72-26$ \\
\hline
\end{tabular}

Double differential cross sections for electrons ejected from $\mathrm{He}$ by $80 \mathrm{keV} \mathrm{H} \mathrm{H}^{+}$in $\mathrm{m}^{2} \mathrm{eV}^{-1} \mathrm{sr}^{-1}$ 
TABLE 11

CROSS SECTIONS FOR $100 \mathrm{keV} \mathrm{H}^{+}$ON He

\begin{tabular}{cccccccccc}
\hline $\begin{array}{c}\text { Energy } \\
(\mathrm{eV})\end{array}$ & 0 & 1 & 2 & 3 & 4 & 5 & 7 & 10 & 20 \\
\hline & & & & & & & & & \\
& & & & & & \\
5 & $4.75-22$ & $2.48-22$ & $2.33-22$ & $2.19-22$ & $2.06-22$ & $1.96-22$ & $1.74-22$ & $1.48-22$ & $9.16-23$ \\
10 & $2.80-22$ & $1.71-22$ & $1.66-22$ & $1.62-22$ & $1.58-22$ & $1.53-22$ & $1.44-22$ & $1.32-22$ & $9.32-23$ \\
15 & $2.82-22$ & $1.91-22$ & $1.86-22$ & $1.80-22$ & $1.73-22$ & $1.68-22$ & $1.56-22$ & $1.39-22$ & $9.02-23$ \\
20 & $2.60-22$ & $2.26-22$ & $2.15-22$ & $2.05-22$ & $1.95-22$ & $1.84-22$ & $1.67-22$ & $1.42-22$ & $8.25-23$ \\
30 & $1.65-22$ & $1.49-22$ & $1.42-22$ & $1.36-22$ & $1.30-22$ & $1.23-22$ & $1.12-22$ & $9.69-23$ & $5.76-23$ \\
40 & $3.76-22$ & $3.44-22$ & $3.21-22$ & $2.96-22$ & $2.72-22$ & $2.46-22$ & $1.99-22$ & $1.41-22$ & $4.83-23$ \\
50 & $7.14-22$ & $5.41-22$ & $4.18-22$ & $3.29-22$ & $2.64-22$ & $2.15-22$ & $1.48-22$ & $9.39-23$ & $3.46-23$ \\
52 & $9.78-22$ & $6.37-22$ & $4.55-22$ & $3.38-22$ & $2.58-22$ & $2.03-22$ & $1.36-22$ & $8.65-23$ & $3.27-23$ \\
54 & $1.39-21$ & $6.49-22$ & $4.51-22$ & $3.25-22$ & $2.42-22$ & $1.87-22$ & $1.23-22$ & $7.76-23$ & $3.06-23$ \\
56 & $1.23-21$ & $3.64-22$ & $2.81-22$ & $2.23-22$ & $1.79-22$ & $1.47-22$ & $1.05-22$ & $7.15-23$ & $2.93-23$ \\
60 & $2.18-22$ & $1.74-22$ & $1.49-22$ & $1.29-22$ & $1.14-22$ & $9.97-23$ & $7.88-23$ & $5.75-23$ & $2.56-23$ \\
70 & $6.36-23$ & $5.91-23$ & $5.75-23$ & $5.54-23$ & $5.29-23$ & $5.02-23$ & $4.44-23$ & $3.58-23$ & $1.89-23$ \\
80 & $3.55-23$ & $3.29-23$ & $3.27-23$ & $3.23-23$ & $3.15-23$ & $3.06-23$ & $2.83-23$ & $2.40-23$ & $1.42-23$ \\
100 & $1.87-23$ & $1.78-23$ & $1.78-23$ & $1.75-23$ & $1.73-23$ & $1.69-23$ & $1.60-23$ & $1.41-23$ & $9.34-24$ \\
\hline
\end{tabular}

\begin{tabular}{ccccccccc} 
Energy & \multicolumn{8}{c}{ Angle (degrees) } \\
$(\mathrm{eV})$ & 30 & 40 & 50 & 60 & 70 & 80 & 90 & 100 \\
\hline & & & & & & & & \\
5 & $6.38-23$ & $4.31-23$ & $2.71-23$ & $1.71-23$ & $1.10-23$ & $6.85-24$ & $5.12-24$ & $4.88-24$ \\
10 & $6.16-23$ & $3.83-23$ & $2.27-23$ & $1.31-23$ & $7.95-24$ & $4.77-24$ & $3.10-24$ & $2.49-24$ \\
15 & $5.38-23$ & $3.13-23$ & $1.80-23$ & $9.88-24$ & $5.69-24$ & $3.27-24$ & $2.01-24$ & $1.69-24$ \\
20 & $4.61-23$ & $2.63-23$ & $1.56-23$ & $8.74-24$ & $4.85-24$ & $2.70-24$ & $1.56-24$ & $1.37-24$ \\
30 & $3.25-23$ & $1.83-23$ & $1.07-23$ & $5.92-24$ & $3.00-24$ & $1.48-24$ & $8.06-25$ & $6.23-25$ \\
40 & $2.37-23$ & $1.31-23$ & $7.70-24$ & $4.15-24$ & $1.99-24$ & $9.50-25$ & $5.21-25$ & $4.27-25$ \\
50 & $1.78-23$ & $1.01-23$ & $5.79-24$ & $3.05-24$ & $1.40-24$ & $6.97-25$ & $3.72-25$ & $2.90-25$ \\
52 & $1.69-23$ & $9.69-24$ & $5.46-24$ & $2.67-24$ & $1.20-24$ & $5.71-25$ & $2.96-25$ & $2.39-25$ \\
54 & $1.62-23$ & $9.20-24$ & $5.15-24$ & $2.52-24$ & $1.14-24$ & $4.89-25$ & $2.59-25$ & $2.56-25$ \\
56 & $1.54-23$ & $8.64-24$ & $4.80-24$ & $2.28-24$ & $1.01-24$ & $4.75-25$ & $2.47-25$ & $2.17-25$ \\
60 & $1.40-23$ & $7.87-24$ & $4.34-24$ & $2.25-24$ & $9.78-25$ & $4.54-25$ & $2.34-25$ & $2.31-25$ \\
70 & $1.08-23$ & $6.09-24$ & $3.15-24$ & $1.42-24$ & $6.19-25$ & $2.97-25$ & $1.66-25$ & $2.18-25$ \\
80 & $8.64-24$ & $4.84-24$ & $2.39-24$ & $1.03-24$ & $4.00-25$ & $1.79-25$ & $1.15-25$ & $1.20-25$ \\
100 & $5.90-24$ & $3.14-24$ & $1.37-24$ & $5.72-25$ & $2.46-25$ & $1.01-25$ & $6.39-26$ & $5.72-26$ \\
\hline
\end{tabular}

Double differential cross sections for electrons ejected from $\mathrm{He}$ by $100 \mathrm{keV} \mathrm{\textrm {H } ^ { + }}$ in m $\mathrm{m}^{2} \mathrm{eV}^{-1} \mathrm{sr}^{-1}$ 


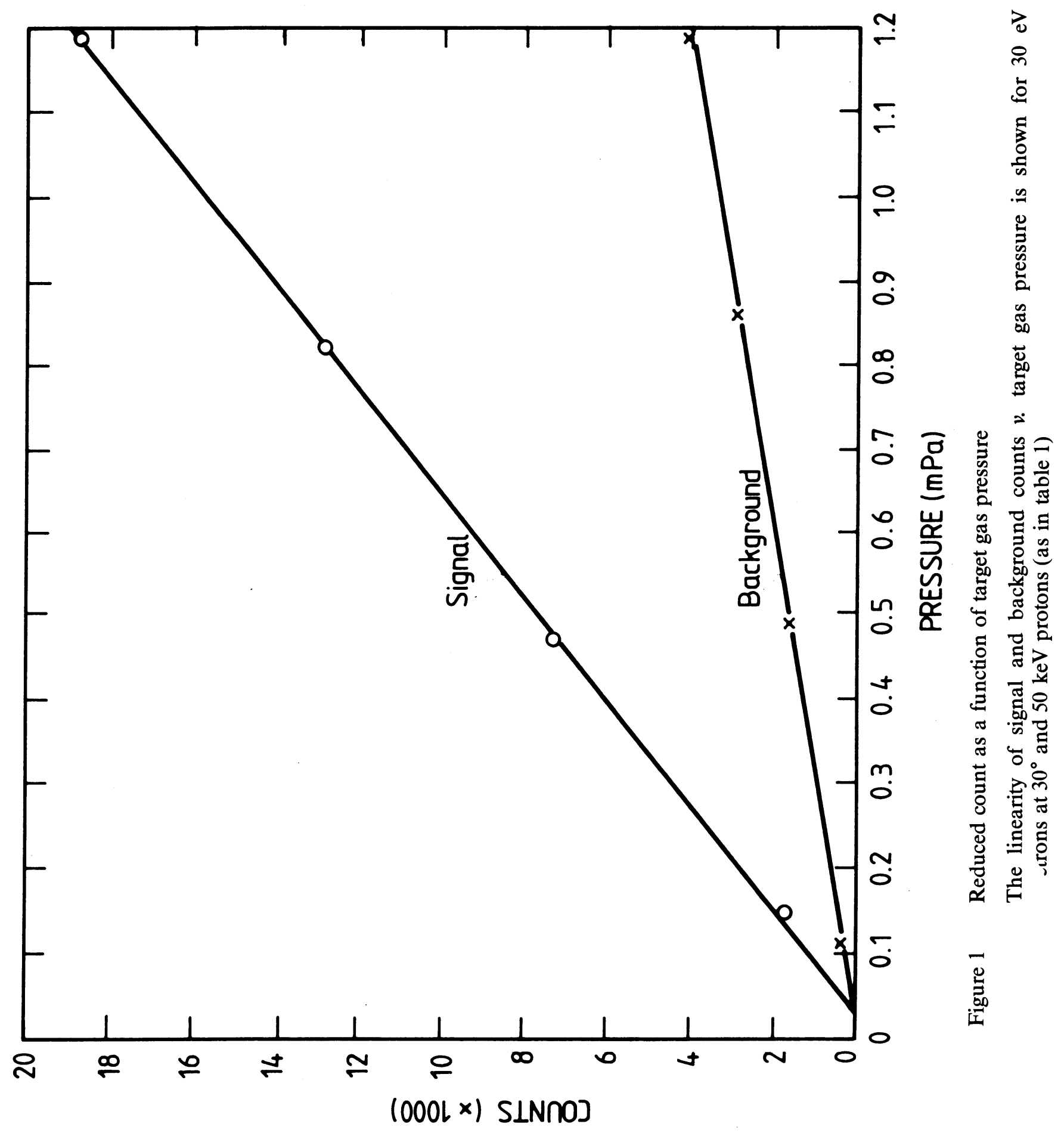




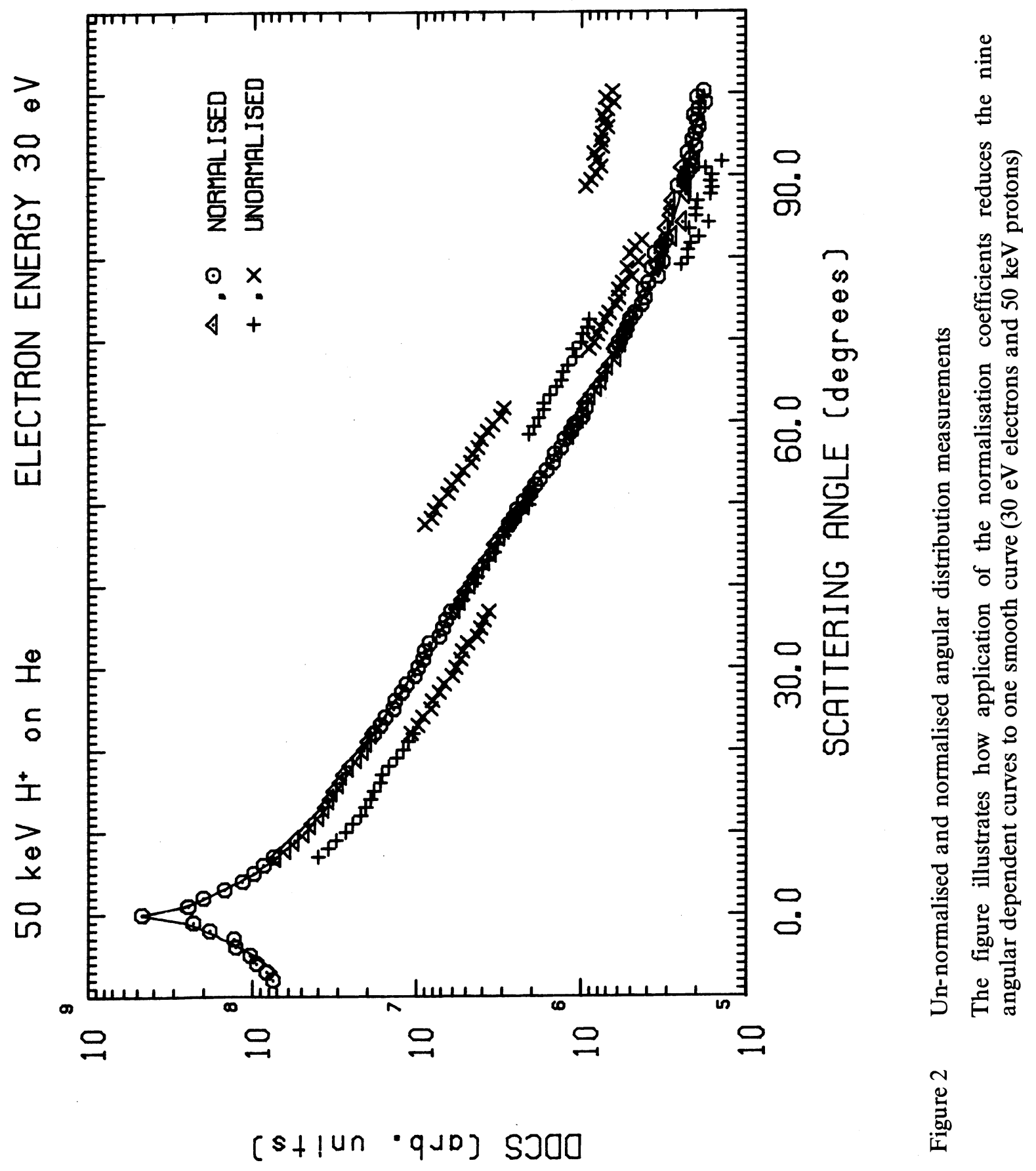




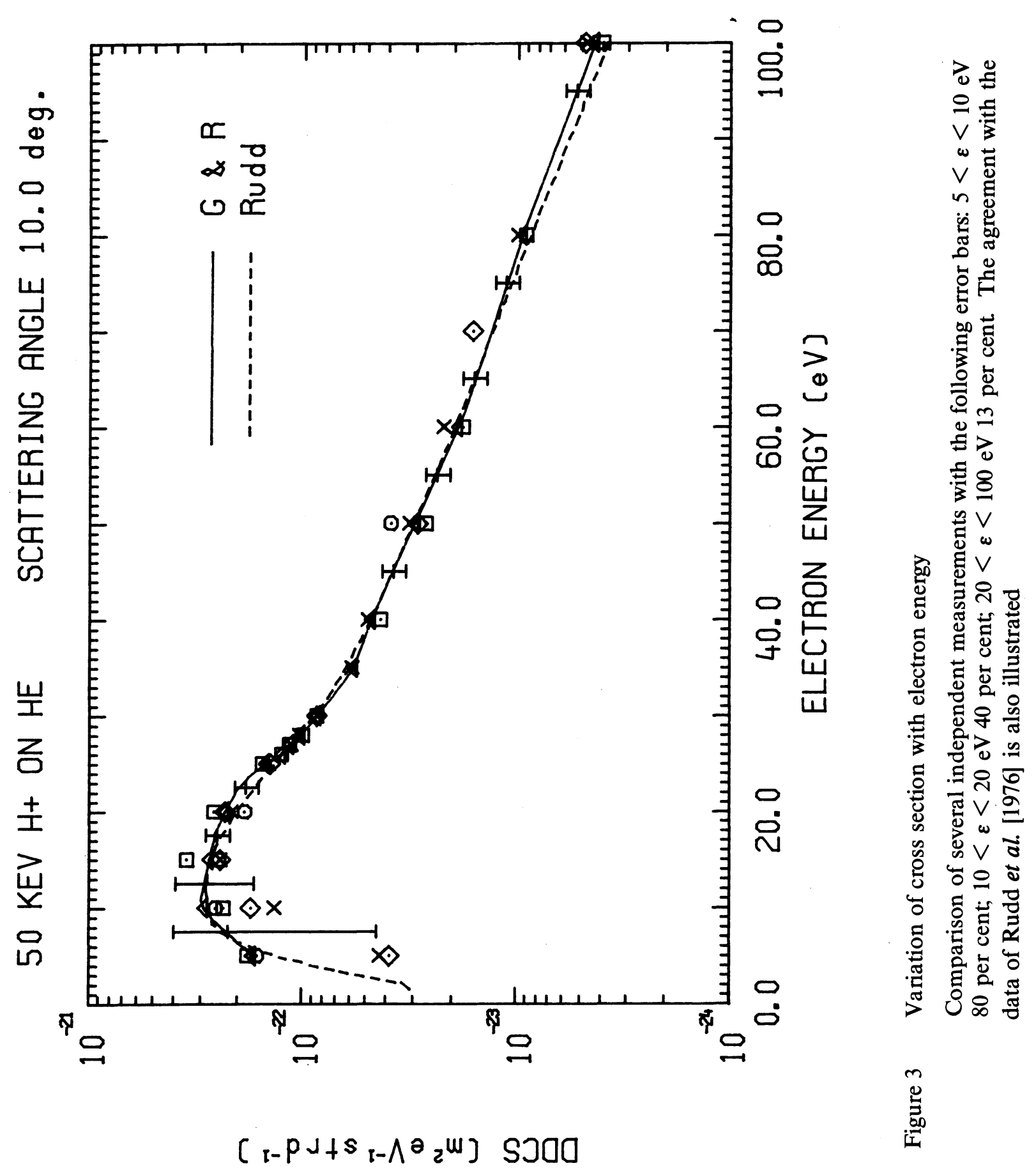




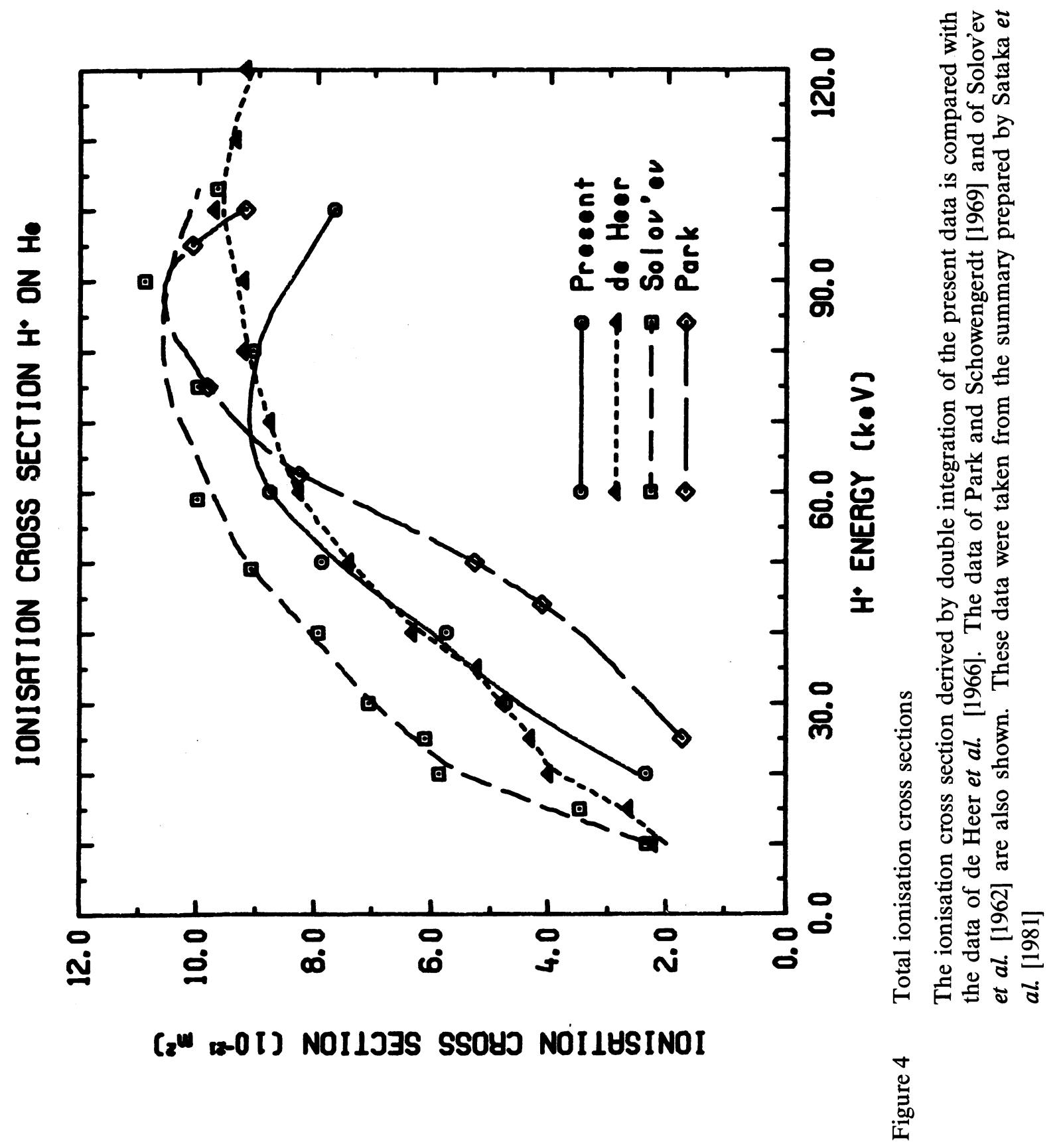




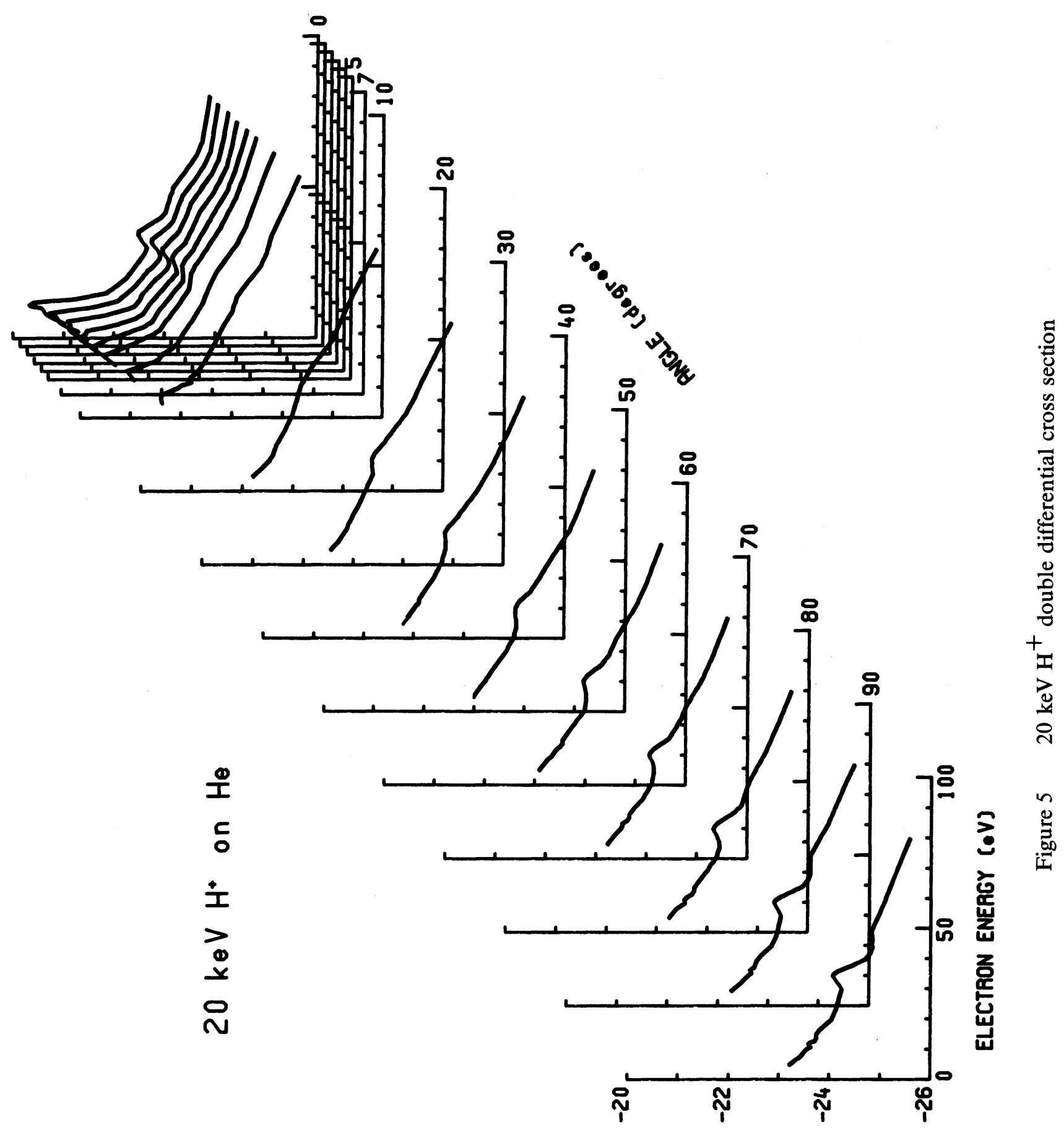

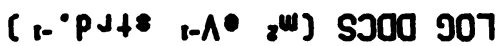




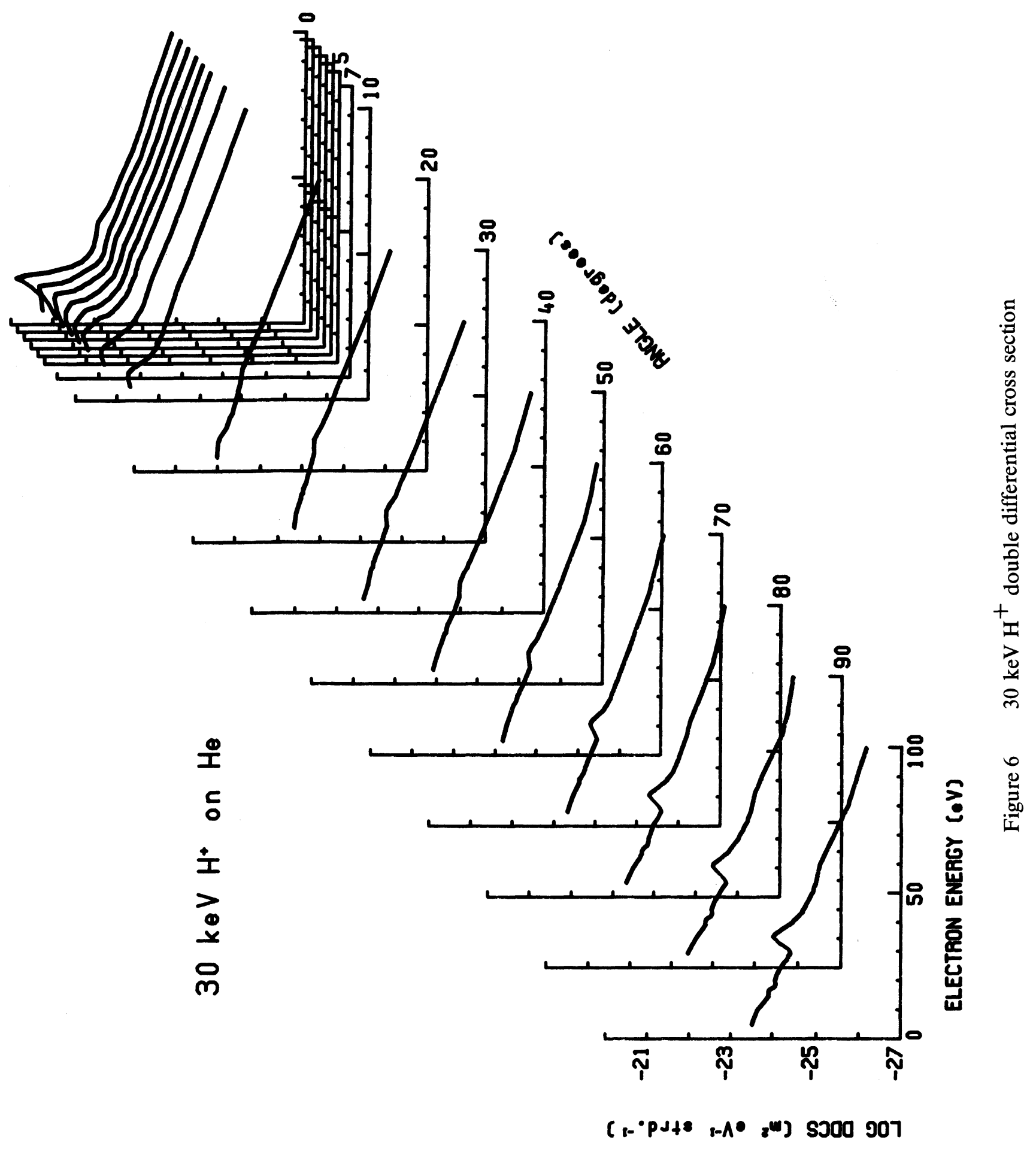




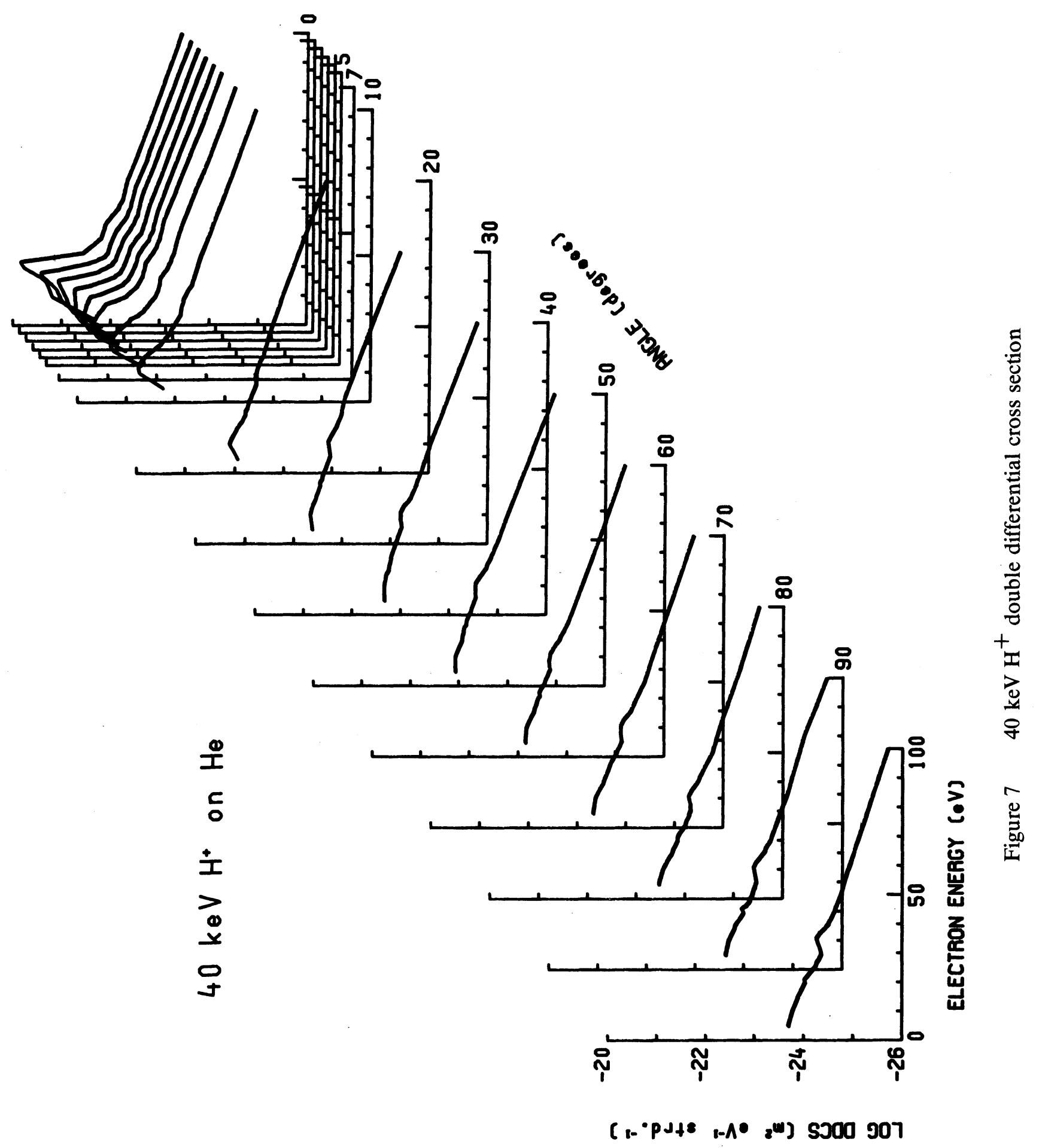




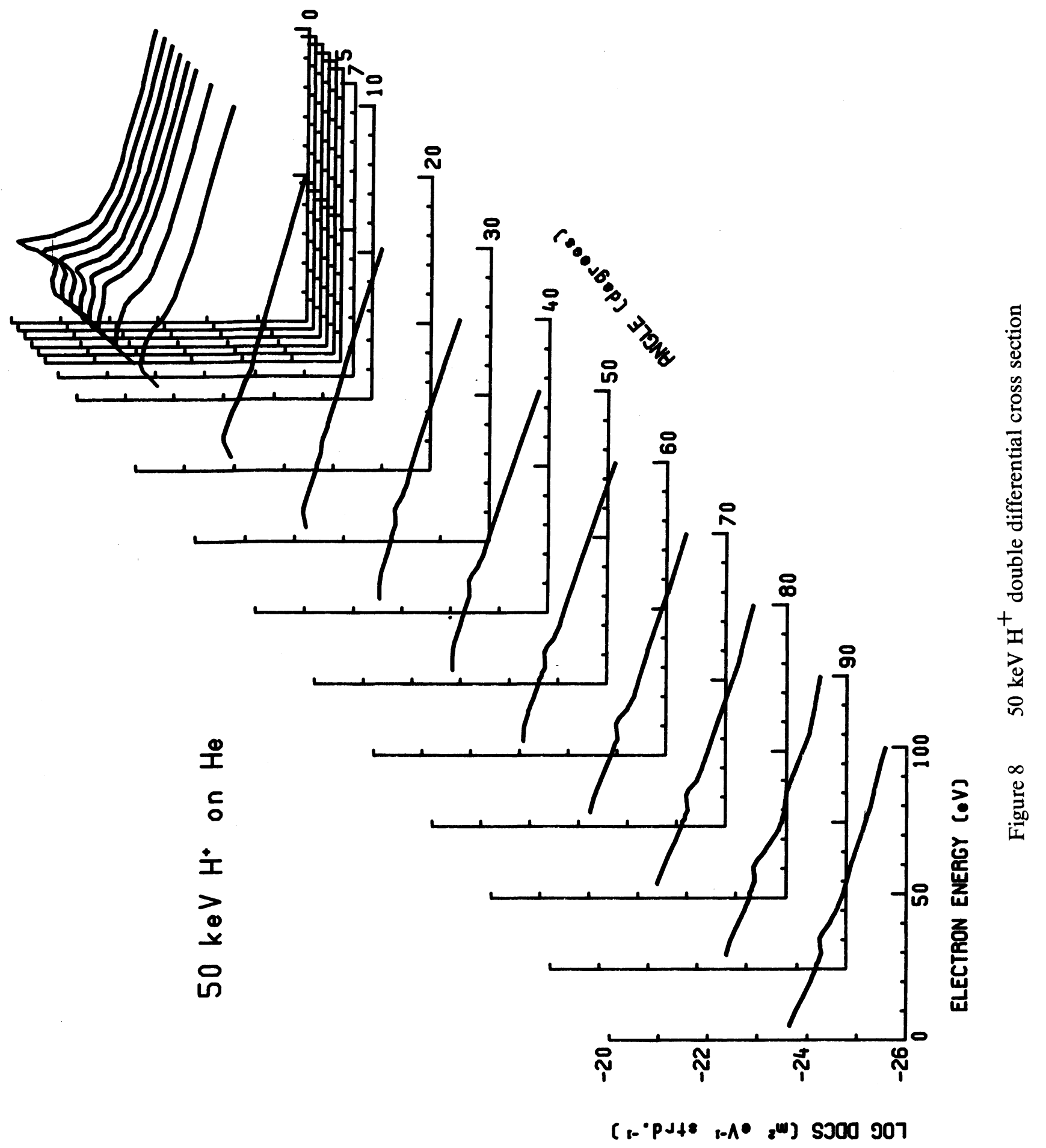




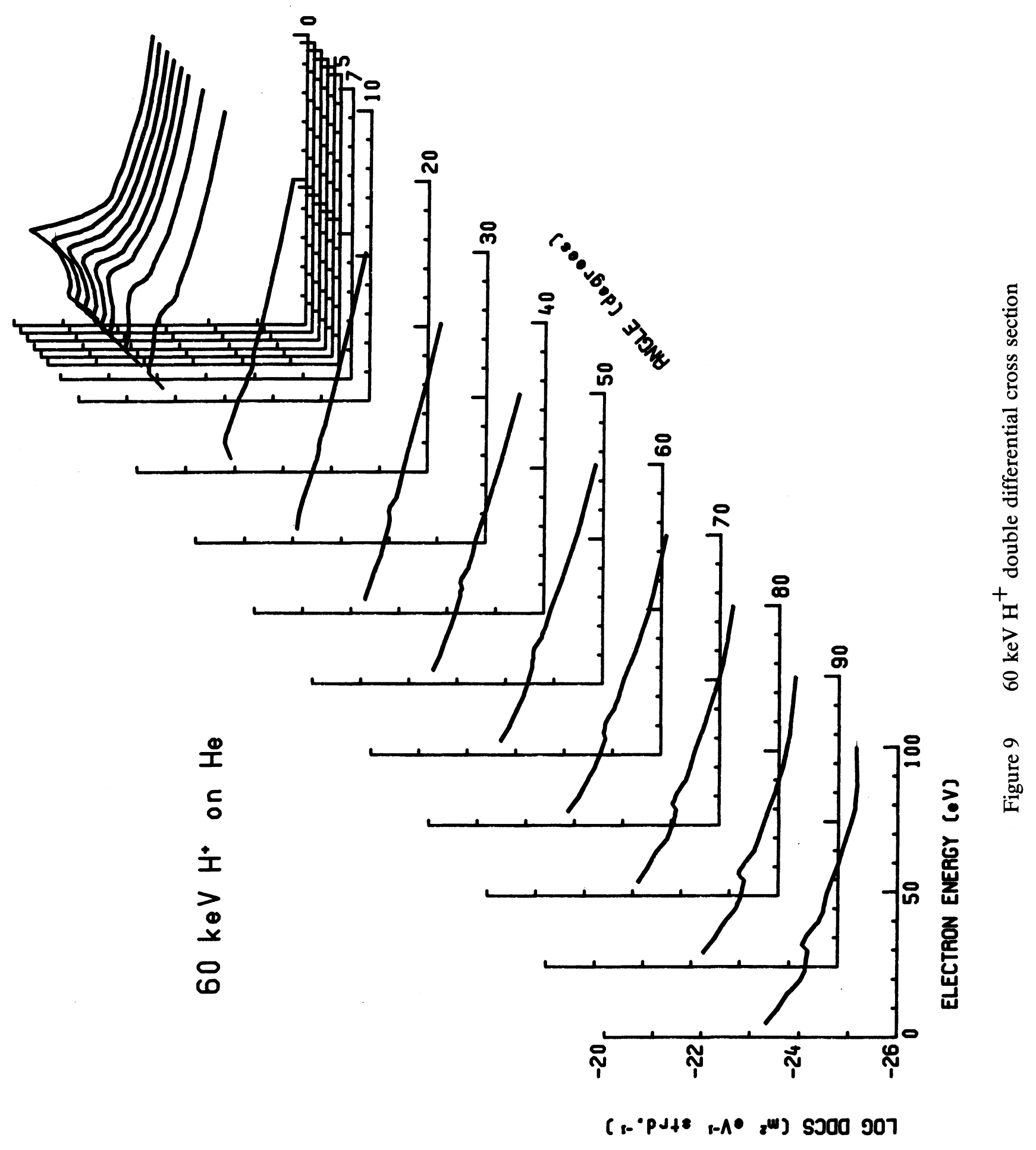




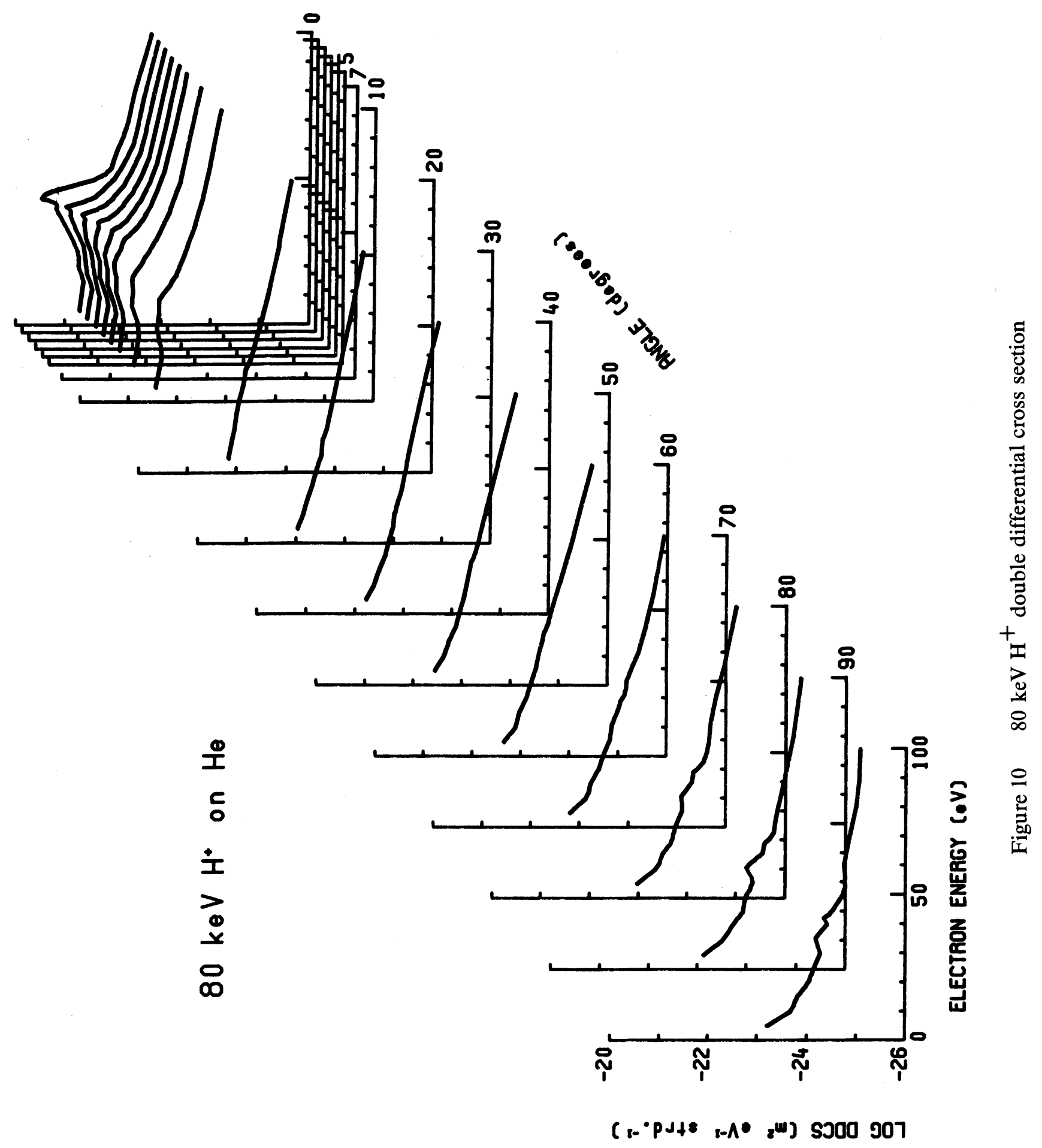




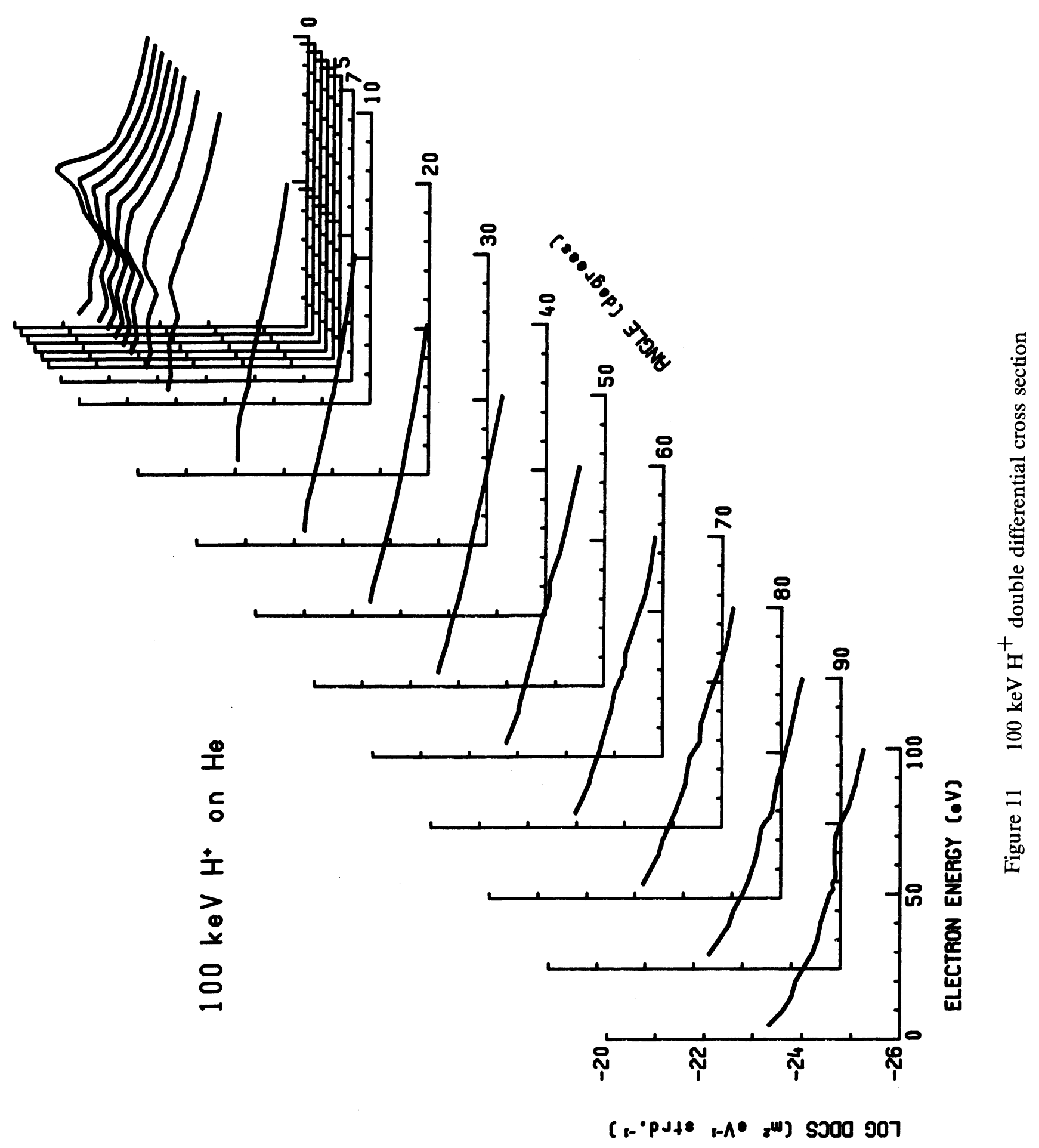

